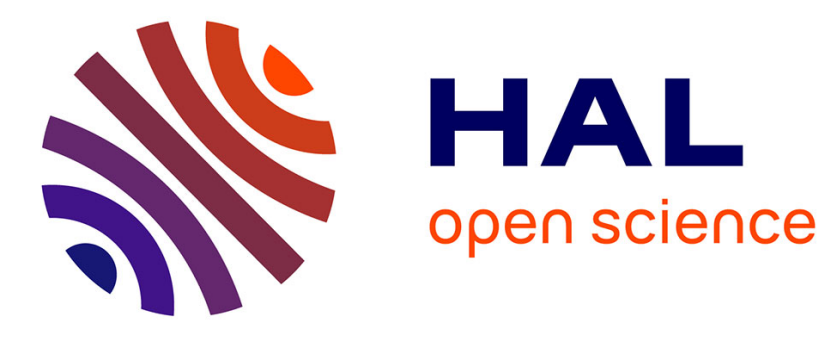

\title{
STOP proteins contribute to the maturation of the olfactory system.
}

Marion Richard, Joëlle Sacquet, Marion Jany, Annie Schweitzer, François Jourdan, Annie Andrieux, Véronique Pellier-Monnin

\section{To cite this version:}

Marion Richard, Joëlle Sacquet, Marion Jany, Annie Schweitzer, François Jourdan, et al.. STOP proteins contribute to the maturation of the olfactory system.. Molecular and Cellular Neuroscience, 2009, 41 (2), pp.120-34. 10.1016/j.mcn.2009.02.004 . inserm-00410222

\section{HAL Id: inserm-00410222}

\section{https://www.hal.inserm.fr/inserm-00410222}

Submitted on 25 Aug 2009

HAL is a multi-disciplinary open access archive for the deposit and dissemination of scientific research documents, whether they are published or not. The documents may come from teaching and research institutions in France or abroad, or from public or private research centers.
L'archive ouverte pluridisciplinaire HAL, est destinée au dépôt et à la diffusion de documents scientifiques de niveau recherche, publiés ou non, émanant des établissements d'enseignement et de recherche français ou étrangers, des laboratoires publics ou privés. 


\title{
STOP proteins contribute to the maturation of the olfactory system
}

\author{
Marion Richard ${ }^{1,2, *}$, Joëlle Sacquet ${ }^{1,2}$, Annie Schweitzer ${ }^{3}$, François Jourdan ${ }^{1,2}$, \\ Annie Andrieux ${ }^{3}$ and Véronique Pellier-Monnin ${ }^{1,2, \#}$
}

\footnotetext{
1 Laboratoire Neurosciences Sensorielles, Comportement, Cognition, CNRS-UMR 5020, Université de Lyon, Lyon 1, F-69366, France.

2 Institut Fédératif des Neurosciences de Lyon, Groupement Hospitalier Est, 69677 Bron Cedex, France.

${ }^{3}$ INSERM, U866, Grenoble Institut of Neurosciences, Team 1 «Pathophysiology of the Cytoskeleton », CEA-Grenoble, iRTSV/GPC, Université Joseph Fourrier, BP170, 38042 Grenoble, Cedex 9, France.

* Present address: Department of Neurosurgery, Yale University School of Medicine, New Haven, CT, USA

\# Present address: INSERM, U842, Lyon, Université de Lyon, Lyon 1, Faculté de Médecine Laennec, UMR-S842, Lyon, F-69372, France.
}

Corresponding author: Marion Richard

Department of Neurosurgery, Yale University School of Medicine, P.O. Box 208082, New Haven, CT 06520-8082, USA

e-mail: marion.richard@yale.edu

Tel: $1-203-785-3230$

Fax: 1-203-737-2159

Keywords: sensory system, olfactory bulb, axon outgrowth, microtubules, cytoskeleton. 


\begin{abstract}
Regulation of microtubule dynamics is crucial for axon growth and guidance as well as for the establishment of synaptic connections. STOPs (Stable Tubule Only Polypeptides) are microtubule-associated proteins that regulate microtubule stabilization but are also able to interact with actin or Golgi membranes. Here, we have investigated the involvement of STOPs during the development of the olfactory system. We first describe the spatio-temporal expression patterns of N- and E-STOP, the two neuronal-specific isoforms of STOP. E-and NSTOP are expressed in the axonal compartment of olfactory sensory neurons, but are differentially regulated during development. Interestingly, each neuronal isoform displays a specific gradient distribution within the olfactory nerve layer. Then, we have examined the development of the olfactory system in absence of STOPs. Olfactory axons display a normal outgrowth and targeting in STOP-null mice, but maturation of the synapses in the glomerular neuropil is altered.
\end{abstract}




\section{INTRODUCTION}

Axon growth and guidance rely on cytoskeleton dynamics, including proteins able to regulate polymerization and stabilization of microtubules, actin and intermediate filaments (Dent and Gertler, 2003). Among the microtubule-associated proteins, STOP proteins (Stable Tubule Only Polypeptides) are reported to confer cold-stability to microtubules (Bosc et al., 2003; Job et al., 1981). Two neuron-specific isoforms, E- and N-STOP, have been identified. E-STOP is known as the early form since its expression is sustained both in the developing brain and in adult, whereas N-STOP isoform appears only after birth (Guillaud et al., 1998). STOP-null mice, deficient for all isoforms, have an apparent normal brain anatomy but display neuroleptic-sensitive behavioral alterations and synaptic plasticity defects, strongly suggesting that they are a valid animal model for the study of human schizophrenia (Andrieux et al., 2002; Brun et al., 2005). Insertion of a LacZ reporter gene in the neuronal STOP locus recently demonstrated expression of STOPs by numerous neuronal populations in the adult and early postnatal brain (Couegnas et al., 2007). However, the precise in situ distribution and function of each neuronal STOP isoform in the developing nervous system remain undetermined. To analyze further the regulation of N- and E-STOP expression related to axon outgrowth and microtubule dynamics, we chose the developing olfactory system as study model.

Olfactory sensory neuron (OSN) axons contact the dendrites of mitral and tufted cells in the glomerular neuropiles of the olfactory bulb. During embryonic development, olfactory axons grow toward the rostral tip of the telencephalon, spread around it and form the olfactory nerve layer (ONL) of the nascent olfactory bulb. Olfactory axons expressing the same molecular odorant receptor converge on a limited number of glomeruli, thereby establishing a precise receptotopic map in the olfactory bulb (Luo and Flanagan, 2007; Mombaerts, 2006; Strotmann and Breer, 2006). Such targeting involves a rearrangement of olfactory axon 
fascicles within the ONL, which can be divided into two anatomical subregions, an outer (oONL) and an inner part (iONL). Axons are randomly fasciculated in the oONL but are sorted and become homotypically associated in the iONL before reaching their target glomerulus (Treloar et al., 2002). The axonal morphology and the cytoskeleton composition of the olfactory axons are highly regulated as they cross the outer and inner ONL and enter the glomerular layer, suggesting the involvement of cytoskeleton regulation in the establishment of the olfactory pathway (Akins and Greer, 2006a; Au et al., 2002; PellierMonnin et al., 2001; Treloar et al., 2002). Thus, the olfactory system appeared a suitable model to study the in situ distribution of neuronal STOP isoforms as well as their contribution to morphogenetic and functional events.

Here, we identify STOP proteins as components of the olfactory axon cytoskeleton. Interestingly, E- and N-STOP isoforms show a specific complementary gradient of distribution in the postnatal olfactory nerve layer, suggesting a fine developmental regulation of their localization within the axonal compartment. We further demonstrate the functional involvement of STOP proteins in the establishment of the olfactory pathway by analyzing the morphology of the olfactory system of STOP-null mice in situ and quantifying the outgrowth ability of $\mathrm{STOP}^{-/}$olfactory axons in vitro. 


\section{RESULTS}

\section{STOP isoforms expression in the developing rat olfactory system}

Using immunohistochemistry, we processed a complete spatio-temporal analysis of the expression of the two neuronal STOP isoforms in the developing rat olfactory system. We therefore used the $\alpha \mathrm{E}$ and 175 antibodies that are specific for E- and N-STOP respectively. At embryonic day E13 (E13), the E-STOP protein was detected in the first olfactory axons emerging from the olfactory epithelium. One day later (E14), the immunopositive olfactory axons coalesced within the lamina propria and formed the presumptive olfactory nerve layer (Fig.1A). At E16, individual stained axons were clearly visible in the lamina propria and the presumptive olfactory nerve layer remained intensely labeled (Fig.1B). E-STOP expression persisted postnatally in olfactory axon fascicles coursing through the lamina propria from postnatal day 1 (P1) (Fig.1C) to adult (Fig.1D). Axons emerging from the vomeronasal organ were also stained by the $\alpha \mathrm{E}$ antibody at all studied developmental stages, as shown for P1 (Fig.1C'). From E18, the olfactory nerve layer (ONL) appeared completely apposed to the olfactory bulb. At this stage, the ONL constituted the most E-STOP-immunoreactive region of the olfactory bulb, while only a moderate staining was visible in the presumptive glomerular layer, the internal plexiform layer and the granule cell layer (Fig.1E). From P1 onwards, immunoreactivity for E-STOP was restricted to the olfactory nerve layer, where it displayed a heterogeneous distribution (Fig.1F). Indeed, the staining appeared more intense in the outer part of the olfactory nerve layer (oONL) compared to the inner part (iONL). Such heterogeneous staining persisted within the ONL during the postnatal development. In the adult olfactory bulb, the labeling intensity was still stronger in the oONL than in the iONL, although the overall E-STOP-immunoreactivity had decreased (Fig.1G).

Our immunohistochemical study revealed that the N-STOP isoform was not expressed in the olfactory system during embryonic development (stages E13-E20), as shown in Fig.2A 
at E14. N-STOP-immunoreactivity appeared at birth in olfactory axon fascicles coursing through the lamina propria and increased at P6 (Fig.2B) and later postnatal stages. Staining for N-STOP persisted in olfactory axon bundles until adulthood (Fig.2C). Background labeling was observed in the connective tissue of the lamina propria and in adult control sections in which primary antibody was omitted (Fig. 2C'). Vomeronasal axons were also NSTOP-immunoreactive from birth to adulthood (data not shown). In the postnatal olfactory bulb, N-STOP-immunoreactivity was confined to the olfactory nerve layer at P6, P15 and in adult (Fig.2D-F). Starting at P6 (Fig.2D), but more evidently at the older stages P15 and adult (Fig.2E and 2F), the olfactory nerve layer displayed a heterogeneous labeling profile, characterized by a stronger immunoreactivity for N-STOP in the inner part of the olfactory nerve layer than in the outer part. In addition, a few sparse immunoreactive fibers were also seen reaching the glomeruli at these postnatal stages.

We further confirmed the heterogeneous and isoform-specific distributions of E- and N-STOP in the olfactory nerve layer of the postnatal olfactory bulb by processing double immunolabelings. For that purpose, we used the glial marker GFAP (glial fibrillary acidic protein) which allows to distinguish the inner from the outer part of the olfactory nerve layer. Indeed, glial cells (astrocytes and/or olfactory ensheathing cells) localized in the glomerular layer and in the iONL are GFAP-immunoreactive, while the olfactory ensheathing cells present in the oONL are known to be GFAP-immunonegative (Au et al., 2002). To optimize the stainings, we chose the P6 stage because the expression of both E- and N-STOP isoforms was sustained at this age. The combination of the anti-GFAP antibody with the 175 antibody (N-STOP-specific) showed the preferential localization of N-STOP in the iONL (Fig.3A-C). Double staining with anti-GFAP and $\alpha$ E antibodies (E-STOP-specific) confirmed the obvious lack of E-STOP staining in the iONL (Fig.3D-F). Finally, combining the two specific anti- 
STOP antibodies ( $\alpha$ E and 175) clearly showed that the E-STOP isoform was concentrated in the oONL, while the N-STOP isoform was expressed robustly in the iONL (Fig.3G-I).

Our in situ analysis showed that STOP proteins are expressed by OSNs and targeted to the olfactory axons. In order to gain more insight in the axonal distribution of STOP isoforms, we used an in vitro model of olfactory epithelium explants. These explants were dissected out of E13 mice embryos and developed a dense network of axons after several days in vitro. STOP proteins were detected in growing olfactory axons by the $23 \mathrm{C}$ (Fig.4A) and $\alpha \mathrm{E}$ antibodies (data not shown), but not by the 175 antibody, indicating the presence of the ESTOP isoform but not the N-STOP. These results were in concordance with our in situ data showing the appearance of N-STOP expression only after birth. In vitro, E-STOPimmunoreactivity was detected along the whole axonal shaft of olfactory axons (Fig.4A) and in axonal varicosities (Fig.4B). E-STOP protein was also present in the central domain of the axonal growth cone, where it displayed a punctuate staining, and in the leading fringe of the lamellipodium as well as in some filopodia, where it colocalized with actin (Fig.4C-E). Note that the thinnest filopodia did not contain E-STOP but displayed only actin staining (asterisk in Fig.4C-E).

\section{In vitro outgrowth ability of STOP-null olfactory axons}

In order to investigate the functional involvement of STOPs in the developing olfactory system, we used the model of the STOP-null mice. These STOP ${ }^{-/}$mice do not express any of the STOP isoforms since the common exon (exon 1) was replaced by a NeoLacZ cassette (Andrieux et al., 2002).

We started our functional study by quantifying the in vitro outgrowth ability of olfactory axons in absence of STOPs. We processed a modified Sholl analysis on olfactory epithelium explants (see Methods section for details) : examples of the maps obtained by this 
analysis are shown in Fig.5A. The mean length of olfactory axons did not differ significantly between wild type $(688 \pm 52 \mu \mathrm{m})$ and STOP $^{-/-}$explants $(659 \pm 62 \mu \mathrm{m})$ (Fig.5B), suggesting that the absence of STOP proteins did not alter olfactory axon outgrowth in vitro. However, the surface covered by the axons with respect to the surface of the explant was reduced for $\mathrm{STOP}^{-/-}$explants $(3 \pm 0.7)$ compared to wild type $(8.2 \pm 1.8, \mathrm{p}=0.04)($ Fig. $.5 \mathrm{C})$.

\section{Morphological analysis of the olfactory system of STOP-null mice}

Although the outgrowth ability of $\mathrm{STOP}^{-/-}$olfactory axons was not profoundly altered in vitro, we further investigated whether the absence of STOPs may rather alter the rearrangement of olfactory axon fascicles within the olfactory nerve layer and/or the glomerular targeting in situ. Supporting this hypothesis was the specific and complementary gradient distribution of the E- and N-STOP isoforms in the olfactory nerve layer, where olfactory axon sorting occurs (Treloar et al., 2002). We focused our analysis on the olfactory nerve layer and the glomerular layer, where olfactory axons end their course and establish synaptic contact with their neuronal target.

At E15, the olfactory epithelium and bulb of $\mathrm{STOP}^{-/-}$embryos do not display any major morphological defects. At this stage, as at older postnatal stages, axons emerge from the olfactory epithelium and course through the lamina propria to contact the olfactory bulb without showing any obvious fasciculation or trajectory defects (Supplementary Fig.1). Glomeruli can be identified in $\mathrm{P} 6 \mathrm{STOP}^{-/-}$embryos as in wild type (WT) controls. However, a morphological analysis of the diameter, the number and the total surface of glomeruli (see Supplementary Fig.2 for details on the method) revealed specific and subtle modifications in postnatal $\mathrm{STOP}^{-/}$mice. Statistical analysis by ANOVA and Bonferroni post-hoc test showed a significant effect of age on the mean glomerular diameter, the number of glomeruli and the total glomerular surface per $\mu \mathrm{m}$ of EPL (Fig.6A-C). In WT mice, the mean glomerular 
diameter significantly increased during postnatal development, from $49.7 \mu \mathrm{m}$ at $\mathrm{P} 6$ to $80.7 \mu \mathrm{m}$ in adult (ANOVA; $\mathrm{F}_{2,6}=53,43 ; \mathrm{p}=1,5 \cdot 10^{-4}$ ). A similar effect of age was visible in $\mathrm{STOP}^{-/-}$ animals since glomeruli displayed a mean diameter of $45.4 \mu \mathrm{m}$ at P6 and $74.8 \mu \mathrm{m}$ in adult (ANOVA; $\mathrm{F}_{2,6}=144,03 ; \mathrm{p}=8 \cdot 10^{-6}$ ). However, while the increase of the mean glomerular diameter occurred continuously from P6 until adulthood in WT mice, it stabilized precociously in $\mathrm{STOP}^{-/-}$mice and did not increase further between P19 and adult age (Fig.6A). The number of glomeruli also increased significantly with time in both groups (Fig.6B) (ANOVA; $\mathrm{F}_{2,6}=8,4 ; \mathrm{p}=0,018$ for WT animals, and $\mathrm{F}_{2,6}=33,2 ; \mathrm{p}=5,7.10^{-4}$ for $\mathrm{STOP}^{-/-}$ mice), as well as the total glomerular surface (Fig.6C) (ANOVA; $\mathrm{F}_{2,6}=88,93 ; \mathrm{p}<10^{-4}$ for WT animals, and $\mathrm{F}_{2,6}=72,89 ; \mathrm{p}<10^{-4}$ for $\mathrm{STOP}^{-/-}$mice).

By comparing the two groups at each developmental stage, no significant difference was observed at P6 and P19 in terms of diameter, number of glomeruli or total glomerular surface (bilateral paired Student $t$ test) (Fig.6D). However, the glomerular morphology appeared altered in adult $\mathrm{STOP}^{-/-}$mice because glomeruli displayed a significantly reduced mean diameter $(p=0.007)$ and were more numerous $(p=0.03)$. Since the total glomerular surface was similar between genotypes (Fig.6D), the decrease of the glomerular diameter appeared compensated for by an increase of the number of glomeruli in adults. This suggests that the number of OSNs is maintained in the olfactory epithelium and that the decrease of the glomerular diameter is not due to a loss of axon terminals. We tested this possibility by measuring the olfactory epithelium thickness in the nasal cavity of P6 and adult animals. No significant difference was observed between the two genotypes at either age (Fig.6D) confirming the maintenance of the number of OSNs, although our results suggested a trend toward a decrease of the olfactory epithelium thickness in adult $\mathrm{STOP}^{-/-}$mice.

\section{Regionalization of the olfactory nerve layer in STOP-null mice}


In light of the specific gradient distribution of STOP proteins in the olfactory nerve layer, we investigated whether the subdivision of this layer in an outer and an inner part may be altered in STOP-null mice. To address this question, we stained olfactory bulb sections for peripherin, a component of the intermediate filaments which is known to be heterogeneously distributed in the inner and outer parts of the olfactory nerve layer (Akins and Greer, 2006a). In accordance with previous report, a sustained immunoreactivity for peripherin was detected in the oONL of WT mice at P6 (Fig.7 A1) and in adult (Fig.7 A3), while the iONL contained a few immunoreactive fibers at P6 and was devoid of staining in adult. Similarly, a heterogeneous distribution was also visible in the olfactory nerve layer of $\mathrm{STOP}^{-/-}$mice at P6 (Fig.7 A2) and in adult (Fig.7 A4). We took advantage of the peripherin staining to measure the relative thickness of the two subregions of the olfactory nerve layer (Fig.7B). The oONL (peripherin-positive) constituted the majority of the olfactory nerve layer in young postnatal and adult WT animals (72.2\% at P6 and $64.2 \%$ in adult). In $\mathrm{STOP}^{-/-}$mice, the percentage of the ONL represented by the outer part did not differ from the WT controls at both ages analyzed (68.8\% at P6 and $66.4 \%$ in adult). These results showed that the subdivision of the olfactory nerve layer was not altered in the absence of STOP proteins.

\section{Olfactory axon targeting in STOP-null mice}

Because the peripherin staining can only reveal large modifications of the regionalization of the ONL, we next asked whether the absence of STOP proteins might induce subtle alterations in the behavior of axons and thereby alter their convergence on a target glomerulus. Therefore, we analyzed two distinct OSN subpopulations which express either the mOR256-17 or mOR28 molecular odorant receptor. Each subpopulation of olfactory axons has been shown to converge on two spatially defined glomeruli (Strotmann et al., 2004; Tsuboi et al., 1999). 
Serial sections were immunostained for mOR28 along the entire anteroposterior axis of the olfactory bulb and only two immunopositive glomeruli were detected in adult $\mathrm{STOP}^{-/-}$ mice as in wild type (Supplementary Fig.3). As previously reported (Tsuboi et al., 1999), one mOR28 glomerulus was detected in the ventrolateral region and the other on the ventromedial side of the most posterior part of the olfactory bulb in wild type mice (Fig.8A and C). mOR28 immunoreactive glomeruli were located at similar positions in the $\mathrm{STOP}^{-/-}$mice (Fig.8B and D). Similarly, mOR256-17 glomeruli were detected at the previously reported positions in both wild type and $\mathrm{STOP}^{-/-}$mice (data not shown): on the dorsolateral side of the anterior olfactory bulb and on the medial side of the posterior olfactory bulb (Strotmann et al., 2004). The margin of error of the position of the mOR256-17 and mOR28 glomeruli did not appear higher than the inter-individual variability already described for several glomeruli (Schaefer et al., 2001; Strotmann et al., 2000). At high magnification, convergence of mOR28 immunoreactive axons within a single glomerulus was evident in adult wild type (Fig.8A' and $\mathrm{C}^{\prime}$ ) and in $\mathrm{STOP}^{-/}$mice olfactory bulbs (Fig.8B' and D') as was the convergence of mOR256-17 immunoreactive axons (Fig.8E and 8F). Our results thus showed that the axon convergence and targeting of the mOR256-17 and mOR28 expressing OSN subpopulations are preserved in absence of STOP proteins.

\section{Compartmental organization of the glomeruli in the olfactory bulb of STOP-null mice}

Our analysis of the $\mathrm{STOP}^{-/-}$olfactory system did not provide any evidence of defects in the ONL regionalization, of olfactory axons mistargeting or of their failure to converge. However, the specific reduction of the glomerular diameter in adult mutant mice led us to ask whether cytoskeleton modifications induced by STOP-deficiency might alter the morphology of the olfactory axon terminal and thereby perturb the organization of the glomerular neuropil. Indeed, the different components of the glomerulus are precisely organized and 
compartmentalized (Kasowski et al., 1999). The axons of the olfactory sensory neurons and the dendrites of projection neurons (mitral and tufted cells) establish synaptic contacts in the glomerulus, but are well segregated. Some earlier studies reported that defects of the glomerular compartmentalization might occur in mutant mice, even without alterations of the olfactory bulb morphology or of axonal convergence. This was the case for $\mathrm{OCAM}^{-/-}$mice that showed a diffuse intermingling of axons and dendrites within glomeruli (Walz et al., 2006). We thus undertook a more detailed quantitative analysis of STOP-null mice by focusing on the compartmental organization of the glomeruli at P6, P19 and adult. We stained olfactory bulb sections with markers specific for the axonal and dendritic compartments of the glomerulus. GAP43 and OMP were the respective markers of the immature and mature olfactory axons, MAP2 was chosen to stain the dendritic compartment and synaptophysin was used as a ubiquitous marker of presynaptic terminals (Kasowski et al., 1999; Kim and Greer, 2000). We quantified the stained glomerular surface as described in Methods. All results and statistical significance are summarized in Table 1. Since results obtained at P19 were similar to those obtained in adult, only the P6 and adult stages are presented here.

At P6 (Fig.9A), the GAP43-positive glomerular surface was wider in the olfactory bulb of STOP ${ }^{-/}$pups $(70.2 \pm 0.4 \%)$ than in WT littermates $(55.2 \pm 2.5 \%)(p=0.004)$. At the same time, a higher percentage of the glomerular surface displayed OMP-immunoreactivity in mutant animals $(46.3 \pm 1.5 \%$ versus wild type $39.9 \pm 1.7 \%)(p=0.05)$. Neither the MAP2nor the synaptophysin-immunoreactive glomerular surfaces differed between genotypes (Fig.9A).

In adult $\mathrm{STOP}^{-/}$animals (Fig.9B), the percentage of the glomerular surface occupied by the axonal markers GAP43 and OMP was restored to the level of the WT controls and the MAP2-immunoreactive surface was equivalent between genotypes. However, the synaptophysin-immunoreactive surface represented a higher percentage of the glomerular 
surface in adult $\mathrm{STOP}^{-/-}$mice $(56.2 \pm 1.7 \%)$ compared to WT littermates $(48.7 \pm 2.2 \%)$ $(\mathrm{p}=0.05)$. Since synaptophysin is a ubiquitous presynaptic marker, we used two other presynaptic markers, VGluT1 and VGluT2 (vesicular glutamate transporter 1 and 2), to specifically stain presynaptic specializations in mitral/tufted cells dendrites and OSN axon terminals respectively (Gabellec et al., 2007; Nakamura et al., 2005). Both the VGluT1 and VGluT2 immunoreactive surfaces represented an equivalent percentage of the glomerular surface in adult wild type and $\mathrm{STOP}^{-/-}$mice (VGluT1: WT $60.9 \pm 4.5 \%$ versus $\mathrm{STOP}^{-/-} 70.1 \pm$ $4.4 \%$; VGluT2: WT $42.9 \pm 3.8 \%$ versus $\mathrm{STOP}^{-/-} 46.1 \pm 8.9 \%$ ).

In conclusion, our results showed that STOP-null mice displayed a transient expansion of the axonal compartment in young postnatal glomeruli and modifications of the synaptophysin-immunoreactive presynaptic terminals in adult glomeruli. 


\section{DISCUSSION}

\section{Preferential distribution of STOP proteins in the axonal compartment of OSNs}

We used the olfactory system as a study model to investigate the in situ expression of neuronal STOP isoforms in relation to axon outgrowth and microtubule dynamics during development. Our data show that E- and N-STOP are both expressed by olfactory sensory neurons, thus confirming previous data reporting STOP expression in the adult and postnatal olfactory system of a $\beta$-galactosidase transgenic reporter line (Couegnas et al., 2007). However, our study provides more precise evidence about the localization of each STOP isoform by using isoform-specific antibodies and about the developmental regulation of their expression since we processed our study from embryonic day E13 until adulthood. While ESTOP is expressed as the first axons grow toward the olfactory bulb at E13 in rat, N-STOP is not detected in the olfactory axons before young postnatal stages. In agreement with these data, N-STOP has only been detected in postnatal brain extracts and appears in differentiated DRG and hippocampal neurons only after 10 to 12 days in culture (Baratier et al., 2006; Guillaud et al., 1998). It is not known yet whether neurons switch from expressing E- to NSTOP during their maturation, or whether mature neurons express both isoforms. In the rat olfactory system, mature $\mathrm{OMP}^{+}$OSNs are detected as soon as E16 (Farbman and Margolis, 1980), well before the postnatal appearance of N-STOP in olfactory axons. Thus our immunohistochemical data favor the hypothesis of E- and N-STOP postnatal coexpression in OSNs rather than a restriction of N-STOP expression to mature OSNs.

Moreover, our in situ and in vitro results both show that STOPs are specifically targeted to the axon and absent from the dendritic compartment in OSNs. Thus, among the MAPs that are expressed in situ in the olfactory system, E- and N-STOP display a distribution similar to MAP1B, which is exclusively present in OSN axons (Schoenfeld et al., 1989; Viereck et al., 1989). Axonal localization of STOPs has also been reported in vitro in DRG 
and hippocampal neurons and reflects the well described interaction of STOPs with microtubules (Bosc et al., 2003; Guillaud et al., 1998). However, the subcellular distribution of STOPs may vary depending upon neuronal cell type since electron microscopy revealed the presence of STOPs in both dendritic spines and axons of adult hippocampal neurons in situ, although the axonal concentration was more abundant (Andrieux et al., 2002).

\section{Differential distribution of STOP isoforms within the olfactory axons in vitro and in situ}

Our data provide the first demonstration of an isoform-specific and heterogeneous in situ distribution of STOPs in axons. Indeed, each neuronal isoform displays a specific gradient distribution in the olfactory nerve layer: E-STOP is the main isoform present in the outer ONL whereas N-STOP is concentrated in the inner ONL. Furthermore, the olfactory axon terminal localized in the glomerular layer appears devoid of STOP proteins in situ. This is slightly different from our in vitro data showing that E-STOP is homogeneously present along the shaft of olfactory axons including the growth cone. The subcellular distribution of STOPs is known to be modulated by its interaction with Calmodulin and by posttranslational modifications such as phosphorylation by CamKII or palmitoylation (Baratier et al., 2006; Gory-Faure et al., 2006). In particular, CamKII-phosphorylated STOPs have recently been reported to bind actin in primary hippocampal neurons (Baratier et al., 2006). Since CamKII is expressed by OSNs (Wei et al., 1998), the colocalization of E-STOP with actin in olfactory axon filopodia is likely to result from the phosphorylation of STOP by CamKII. Calmodulin is present in OSNs too (Biffo et al., 1991) and may contribute to the regulation of STOP subcellular distribution. Therefore, one can speculate that the in situ and in vitro environments would differentially modulate CamKII and Calmodulin activities in olfactory sensory neurons and thereby modify the distribution of STOPs within the axonal compartment. It should be noted that the discordance between a heterogeneous in situ distribution and a homogenous in 
vitro staining within olfactory axons is not restricted to STOP proteins. Indeed, other microtubule-associated proteins and microtubules components such as MAP1B and $\beta$-tubulin share this characteristics (Pellier-Monnin et al., 2001; Richard et al., 2005). Collectively, these results suggest that cytoskeleton composition and dynamics may be regulated by the interaction of the olfactory axon with its in situ environment, notably with its synaptic target and the olfactory ensheathing cells. Indeed, these glial cells display a differential expression pattern of signaling and adhesion molecules within the inner and the outer parts of the olfactory nerve layer in situ (Hisaoka et al., 2004; Ubink et al., 1994; Ubink and Hokfelt, 2000) and might thereby influence the compartmentalization of proteins within the olfactory axon.

\section{Dynamics of the axonal cytoskeleton within the olfactory nerve layer and glomeruli}

E- and N-STOP extend the increasing list of proteins associated with the axonal cytoskeleton that exhibit a heterogeneous distribution pattern within the olfactory nerve layer in situ. Indeed, peripherin and $\alpha$-internexin, two constituents of the intermediate filaments, as well as SCG10 and stathmin, two microtubule-associated proteins, and $\gamma$-catenin, which links plasma membrane cadherins to the cytoskeleton, are enriched in the outer ONL compared to its inner part (Akins and Greer, 2006a, 2006b; Pellier-Monnin et al., 2001). However, to our knowledge, N-STOP is the first cytoskeleton associated protein to be reported as enriched in the inner ONL. Interestingly, concomitant to the regulated distribution of some cytoskeleton components, the subdivision of the ONL also reflects modifications of the axonal morphology and behavior. Indeed, olfactory axons are randomly fasciculated when they enter the oONL but are sorted according to their molecular odorant receptor and display an increased diameter within the iONL, once they have reached the broad region of their target glomerulus (Akins and Greer, 2006a, 2006b; Treloar et al., 2002). Generally, proteins interacting with 
microtubules, intermediate filaments and actin regulate their polymerization, stabilization or disassembly and thereby determine both the rate and the direction of neurite outgrowth as well as the axonal diameter and ramification process. In the olfactory system, the complementary gradient distributions of STOPs may contribute to controlling the axonal diameter within the ONL (Akins and Greer, 2006a) through a specific function of each isoform, notably because N-STOP may interact with an unknown partner via its unique Cterminal sequence that is absent in E-STOP (Bosc et al., 2003). In the glomeruli, the olfactory axon terminals, similar to most presynaptic specializations (Dillon and Goda, 2005), appear devoid of microtubules, intermediate filaments, and microtubule-stabilizing proteins such as MAP1B and STOPs, but are enriched in actin. This dynamic cytoskeleton composition could favor the ramification of olfactory axon terminals that occurs specifically within their target glomerulus (Akins and Greer, 2006a; Chien et al., 1998; Gorham et al., 1991; Klenoff and Greer, 1998; Pellier-Monnin et al., 2001).

Numerous data show that the cytoskeleton composition is highly regulated within the axonal compartment as olfactory axons cross the ONL and enter their target glomerulus in the olfactory bulb. However, the hypothesis of a functional involvement of cytoskeleton components in the establishment of the primary olfactory pathway has never been tested. Because of their isoform-specific and complementary gradient distributions within the ONL, E- and N-STOP might be promising cytoskeleton candidates involved in olfactory axon sorting and glomerular targeting. We investigated such a potential implication of STOPs by analyzing the olfactory system of STOP-null mice in vitro and in situ.

\section{Functional implication of STOP proteins in the development of the olfactory pathway}

$\mathrm{STOP}^{-/}$embryonic olfactory epithelium explants displayed no significant alteration of the axonal length, suggesting that STOPs are not necessary to OSN axon outgrowth in vitro. 
In accord with this data, $\mathrm{STOP}^{-/-}$primary hippocampal neurons do not show any axon outgrowth defect after 3 days in vitro (Andrieux unpublished observations). In contrast, depletion of STOPs by microinjecting antibodies or transfecting anti-sense oligonucleotides has been previously shown to reduce the formation of neurites in PC12 cells (Guillaud et al., 1998). Thus, the absence of STOPs may be more or less deleterious depending on the neuronal population and the method of inactivating STOPs. The decrease of the ratio axonal surface/explant surface observed in $\mathrm{STOP}^{-/-}$olfactory epithelium explants might reflect a reduction of the number of axons due to a decrease of the OSNs population or a reduction of their ramification ability. We favor the second hypothesis because the olfactory epithelium thickness is preserved in situ in $\mathrm{STOP}^{-/-}$animals, suggesting no modification of the OSNs number. Alteration of the axonal ramification ability without reduction of the axonal length has already been described for $\mathrm{MAP}^{-\mathrm{B}^{--}}$adult DRG neurons in vitro, suggesting that some MAPs could be specifically involved in neurite ramification rather than straight outgrowth (Bouquet et al., 2004).

Consistent with our in vitro results, the gross morphology of embryonic and postnatal $\mathrm{STOP}^{-/-}$olfactory system appears normal in situ and defects were mainly detected in adult animals. The integrity of the olfactory pathway was preserved, as assessed by the ONL regionalization or the targeting and convergence of mOR28 and mOR256-17 immunoreactive axons. However, $\mathrm{STOP}^{-/-}$olfactory bulbs show a precocious stabilization of the glomerular diameter during development, resulting in smaller glomeruli in adult mutant mice compared to wild type. Moreover, the increase of the number of glomeruli in the adult STOP-null mice suggests a duplication of some glomeruli. However, we were not able to detect this kind of duplication for the two OSN subpopulations expressing mOR256-17 or mOR28. This result suggests that if this duplication occurs, it does not affect all the glomeruli, although caution should be used when extrapolating the results obtained with two OSN subpopulations to the 
thousand of existing molecular odorant receptors. A previous study did not report any difference in the number of glomeruli or in their diameter in adult $\mathrm{STOP}^{-/-}$mice (Andrieux et al., 2002) but such discrepancy may rely on methodological considerations since the diameter reduction was very slight (only $6 \mu \mathrm{m}$ ). Moreover, the decrease of the glomerular diameter is consistent with the overall trend toward a brain reduction reported in STOP-null mice but affecting significantly only discrete regions (Powell et al., 2007). In accordance with the expression patterns of E- and N-STOP, examination of the glomerular compartmentalization in $\mathrm{STOP}^{-/}$mice showed that modifications are restricted to OSNs axons while mitral cell dendrites appear normal at P6. Several other brain regions are reported to display intact dendritic shafts and arborization as well as a normal expression of MAP2 mRNA in adult STOP-null mice (Andrieux et al., 2002; Eastwood et al., 2007). The limited defects of the $\mathrm{STOP}^{-/-}$olfactory system are likely explained by the redundancy of microtubule-associated proteins expressed by OSNs and especially those present in the ONL, such as MAP1B, stathmin and SCG10 (Camoletto et al., 2001; Pellier-Monnin et al., 2001; Schoenfeld et al., 1989). Among the proteins able to compensate the absence of STOPs, SL21, a recently identified STOP like protein of $21 \mathrm{kDa}$, might be an interesting candidate if it occurs in the olfactory system (Gory-Faure et al., 2006).

The maintenance of the total glomerular surface and of the olfactory epithelium thickness suggests that the reduction of the glomerular diameter in adult STOP-null mice is not due to a loss of OSNs. Interestingly, the smaller glomerular diameter observed in situ could thus be a consequence of the decreased ramification ability of STOP ${ }^{-/-}$OSN axons reported in vitro. The in situ effect might be only visible in adult and not earlier during development because axonal ramification is known to progressively increase within the postnatal olfactory glomeruli (Klenoff and Greer, 1998). Thus, the limited in vitro defects and the late apparition of deficits during in situ development in STOP-null mice suggest that 
neuronal STOP proteins may be necessary to the maturation of the olfactory system rather than to its initial development. A recent study reported post-pubertal emergence of behavioral deficits in STOP-null mice. The adult mutant mice had higher levels of locomotor activity in open field tests and a greater increase in locomotor activity when exposed to a mild stress, relative to controls (Begou et al., 2007). These results and ours both show progressive developmental alterations occurring in the mouse model, which are similar to the symptoms emergence during adolescence and early adulthood in human schizophrenia. Moreover, defects in the $\mathrm{STOP}^{-/-}$olfactory system are reminiscent of the olfactory bulb and cortex sizereduction observed in schizophrenic patients (Turetsky et al., 2003; Turetsky et al., 2000; Wright et al., 2000). Together, these results, associated to the report of a genetic association between STOP and schizophrenia (Shimizu et al., 2006) and the dopaminergic deficits of $\mathrm{STOP}^{-/-}$mice (Bouvrais-Veret et al., 2008), provide strong support to STOP-null mice candidacy as a model of human schizophrenia. Interestingly, schizophrenic patients display alterations of olfactory sensory neuron turnover in the olfactory epithelium (Arnold et al., 2001; Feron et al., 1999; McCurdy et al., 2006; Smutzer et al., 1998) and modifications of the dendritic compartment in the olfactory bulb (Rioux et al., 2005; Rioux et al., 2004). Discrepancy in histological defects between the mouse model and the human pathology may be due to the post mortem origin of human tissue as well as the antipsychotic drugs taken by most of the patients. Indeed, long-term treatments with neuroleptics or Epothilone D not only alleviate behavioral and synaptic plasticity deficits but also partially restore histological defects in STOP-null mice (Andrieux et al., 2006).

\section{Involvement of STOP proteins in synaptic maturation in the olfactory system}

Synaptic defects have been reported in restricted brain regions of adult $\mathrm{STOP}^{-/}$mice, such as modifications of synaptophysin mRNA expression, reduction of the pool of synaptic 
vesicles as well as synaptic transmission dysfunctions (Andrieux et al., 2002; Brun et al., 2005; Eastwood et al., 2007). The absence of STOPs might alter the microtubule-based transport and thereby impair the synaptic vesicle trafficking through either the disorganization of the microtubule tracks or the disregulation of the association of the motor proteins kinesin and dynein as recently demonstrated for Tau (Dixit et al., 2008; Vershinin et al., 2007). This effect might be particularly important at branching points and to switch cargoes from microtubules- to actin-based transport at axon terminals. STOPs, which are able to bind both microtubules and actin (Baratier et al., 2006), would be particularly interesting candidates for assuming such function.

In the olfactory system, modification of the synaptophysin staining suggests that the absence of STOPs leads to synaptic defects within the olfactory glomeruli. However, since neither VGluT1 nor VGluT2 staining displays similar alterations, additional experiments are needed to localize and characterize the exact nature of the presynaptic modifications occurring in the adult $\mathrm{STOP}^{-/}$glomeruli. Interestingly, synaptophysin-immunoreactivity is modified upon maturation in the developing olfactory system of wild type mice, with immature glomeruli of young postnatal animals displaying a more uniform staining than mature glomeruli in adults (Johnson et al., 1996; Kim and Greer, 2000). Thus, our observation of a wider synaptophysin-immunoreactive surface in adult $\mathrm{STOP}^{-/}$glomeruli further confirms the alteration of the final glomerular maturation, as suggested above by their reduced diameter.

How could the presynaptic structural modifications within glomeruli explain the olfactory dysfunction observed in $\mathrm{STOP}^{-/-}$mice? Limited histological deficits are consistent with the success of mutants in the buried food test, which rules out the possibility of anosmia (Powell et al., 2007) but it would also be interesting to investigate $\mathrm{STOP}^{-/-}$mice olfactory detection thresholds. Modifications of the synaptic vesicles pool may alter synaptic plasticity 
such as long term potentiation which occurs in the olfactory system at the level of the glutamatergic synapse from OSN axons to mitral cell dendrites (Ennis et al., 1998). Longterm potentiation and depression are decreased in $\mathrm{STOP}^{-/-}$hippocampus (Andrieux et al., 2002) and could also be affected at the primary olfactory synapse. Alteration of synaptic plasticity may contribute to the learning deficits in odor-reward association and long term memory assessed by olfactory discrimination displayed by adult $\mathrm{STOP}^{-/-}$mice (Powell et al., 2007). In addition, since the olfactory memory deficits reported in $\mathrm{STOP}^{-/-}$mice are reminiscent of those described in schizophrenic patients (Moberg et al., 1999), they are likely to result from cortical histological defects like human symptoms (Arnold et al., 1991; Turetsky et al., 2003).

In conclusion, our data report an isoform-specific distribution of neuronal STOP proteins within the olfactory sensory neuron axons. The olfactory bulb of adult STOP-null mice displays presynaptic defects concordant with an involvement of STOPs in synaptic maturation, as occurs in other adult brain regions. Our results are concordant with STOP-null mice candidacy as a mouse model of human schizophrenia, which is currently considered as resulting from developmental alterations affecting synaptic function (Owen et al., 2005). 


\section{EXPERIMENTAL METHODS}

\section{Animals}

Wistar-SPF rat embryos from the $13^{\text {th }}$ to the $20^{\text {th }}$ day of gestation (day of conception $=$ E1) and rats aged of 1, 6, 15 and 40 postnatal days (day of birth $=$ P1) were purchased from Charles River (St Germain sur l'Arbresle, France). For each developmental stage, at least two different litters were used. Homozygous STOP-null mice $\left(\mathrm{STOP}^{-/}\right)$and their wild type littermates (WT, $\mathrm{STOP}^{+/+}$) were generated as previously described (Andrieux et al., 2002). The phenotype of STOP-null animals was analyzed at embryonic day (E) E15, postnatal stages (P) P1, P6, P19 and in adult (8 weeks). All animals used in this study arose from the same colony (BALBc/129 Sv background). All experiments were done blind to genotype. Animals were kept in a 12-hours light/dark cycle and provided with food and water ad libidum. The handling of animals was conducted according to European Community Council Directive (86/609/EEC) and French Ethical Committee for the care and use of laboratory animals.

\section{Antibodies}

Different antibodies directed against STOP proteins were used in this study. The rabbit polyclonal $23 \mathrm{C}$ antibody targets a peptide in the $\mathrm{COOH}$-terminal domain of the rat brain STOP central repeat motif and thus recognizes all STOP isoforms (Bosc et al., 1996; Guillaud et al., 1998). The mouse monoclonal 175 antibody specifically recognizes N-STOP by binding to its unique COOH-terminal repeats (Pirollet et al., 1992). The rabbit polyclonal antibody $\alpha \mathrm{E}$ was raised by Eurogentec (Seraing, Belgium), against peptide CEQSKEMNNKLAEAKE. The peptide corresponds to the C-terminus of mouse E-STOP (aa 554-568, according to NCBI's RefSeq accession number NP_001041632). The cysteine residue was introduced for the coupling to the protein carrier. The specificity of each STOP 
antibody was assessed by western blot analysis on protein extracts from adult wild type and STOP-null mouse olfactory bulb (see Supplementary Fig.4).

The primary and secondary antibodies used in this study, as well as their working dilution, are summarized in Table 2. In addition to the different anti-STOP antibodies (23C, $\alpha \mathrm{E}, 175)$, we used antibodies raised against the astrocytic marker glial fibrillary acidic protein (GFAP) or two OSN markers, the growth-associated protein of 43kDa (GAP43) and the olfactory marker protein (OMP). The dendritic marker microtubule-associated protein 2 (MAP2), the synaptic vesicle marker synaptophysin, the vesicular glutamate transporters VGluT1 and 2, the intermediate filament protein peripherin, and the molecular olfactory receptors mOR256-17 or mOR28 were also targeted with specific antibodies. In addition, we used a $\beta$ III-tubulin antibody and TRITC-conjugated phalloidin to stain respectively axonal tubulin and actin.

\section{Preparation of tissues}

Time-pregnant dams were deeply anesthetized with Equithesin $(0.5 \mathrm{ml}$ per $100 \mathrm{~g}$ body weight) and embryos obtained by cesarean section. Embryos were quickly decapitated and heads were immersed in cold fixative during 4 hours for younger embryos and overnight for the others. The fixative was periodate-lysine-paraformaldehyde (PLP), consisting of $2 \%$ paraformaldehyde, $75 \mathrm{mM}$ lysine, $10 \mathrm{mM}$ sodium m-periodate in $50 \mathrm{mM}$ phosphate-buffered saline (PBS) (McLean and Nakane, 1974). Postnatal and adult animals were deeply anesthetized with Equithesin and transcardially perfused with a Ringer's solution followed by the same fixative. The nasal cavity and the olfactory bulbs were carefully dissected out and post-fixed overnight at $4^{\circ} \mathrm{C}$. All tissues were then cryoprotected in sucrose $(20 \%$ in PB 100 $\mathrm{mM}$ ), frozen at $-55^{\circ} \mathrm{C}$ in nitrogen-cooled isopentane and stored at $-75^{\circ} \mathrm{C}$ until use. Coronal 
sections $\left(14 \mu \mathrm{m}\right.$-thick) were cut serially on a Leitz cryostat at $-20^{\circ} \mathrm{C}$ and thaw-mounted on gelatin-coated glass slides for immunohistochemistry (stored at $-20^{\circ} \mathrm{C}$ until use).

\section{Immunohistochemistry}

Sections were air-dried for $10 \mathrm{~min}$ at room temperature and rehydrated in PBS $(\mathrm{pH}$ 7.4). They were then permeabilized in PBS-triton X100 (0.1\%) solution and preincubated in blocking buffer (5\% bovine serum albumin and 5\% normal serum from the species of origin for the appropriate secondary antibodies, in PBS-triton X100) for $90 \mathrm{~min}$ at room temperature to block non-specific binding. Primary antibodies were diluted in the blocking solution and applied on the sections overnight at $4^{\circ} \mathrm{C}$. Simultaneous double-staining experiments were processed by mixing both primary antibodies. After rinsing with PBS, secondary antibodies (see Table 2) were diluted in a blocking solution devoid of triton X100 and applied on the sections for $90 \mathrm{~min}$ at room temperature. The immunostaining protocol was slightly modified for mOR28, VGlut1 and VGluT2 by using a blocking solution composed of PBS $0.3 \%$ triton $\mathrm{X} 100$ and $5 \%$ bovine serum albumin. At the end of the staining procedure, sections were mounted using Vectashield (Vector Lab) that occasionally contained DAPI. Sections were examined with either a Zeiss or Olympus BX51 fluorescence microscope. Digitized images were processed for adjustment of brightness and contrast with an image-editing software (Adobe Photoshop 7.0).

\section{Explants}

\section{Dissection and culture}

Olfactory epithelium explants were dissected as previously described (Richard et al., 2005). The procedure was adjusted for the mouse by using E13 embryos. Briefly, explants were plated on cover-slips coated with $100 \mu \mathrm{g} / \mathrm{mL}$ poly-L-lysine (Sigma-Aldrich) and 20 
$\mu \mathrm{g} / \mathrm{mL}$ laminin (Roche Diagnostics). Culture medium contained gentamycin $(100 \mu \mathrm{g} / \mathrm{mL})$, glucose $(6 \mathrm{mg} / \mathrm{mL})$, insulin $(5 \mu \mathrm{g} / \mathrm{mL})$, glutamin $(2 \mathrm{mM})$, bovine serum albumin $(1 \%)$, holotransferrin $(10 \mu \mathrm{g} / \mathrm{mL})$, putrescin $(0.1 \mathrm{mM})$, ascorbic acid $(40 \mu \mathrm{M})$ and sodium selenite $(30$ $\mathrm{nM})$ diluted in DMEM and HAM F12 media (1:1 mixture). Products were from Eurobio and Sigma-Aldrich Company. Methylcellulose (0.4\%, Fluka, Sigma-Aldrich) was added to the culture medium in order to ensure better adherence of the tissue on the cover-slip. Explants were maintained at $37{ }^{\circ} \mathrm{C}$ and $5 \% \mathrm{CO}_{2}$.

\section{Immunocytochemistry}

The distribution of STOP proteins was revealed in explants by fluorescent immunocytochemistry, whereas chromogenic immunocytochemistry was preferred to stain for $\beta$ III-tubulin in order to perform the neurite outgrowth quantification.

Briefly, explants were fixed after 4 days in vitro, by overnight immersion in paraformaldehyde (4\% in PBS) at $4{ }^{\circ} \mathrm{C}$. They were incubated during $2 \mathrm{~h}$ in a blocking solution $(0.2 \%$ triton X100, $5 \%$ bovine serum albumin and 5\% normal horse serum, in PBS $)$ and then overnight at $4^{\circ} \mathrm{C}$ with the primary antibody. After rinsing in PBS, the appropriate secondary antibody (see Table 2) was applied to the sections during $2 \mathrm{~h}$ (in blocking buffer without triton X100). For $\beta$ III-tubulin chromogenic staining, explants were further incubated with the ABC complex (Avidin Biotin Complex) for $90 \mathrm{~min}$ following manufacturer indications (Vectastein Elite kit, Vector Labs). Peroxydase enzymatic activity was revealed by incubation with a developing solution containing $0.05 \%$ DAB (3,3'-diaminobenzidine tetrahydrochloride), $0.5 \%$ ammonium nickel sulfate and $0.003 \% \mathrm{H}_{2} \mathrm{O}_{2}$ in $0.05 \mathrm{M}$ Tris buffer $(\mathrm{pH} 7.6)$.

\section{Axon outgrowth quantification}

To quantify axon outgrowth, we processed a semi-quantitative analysis derived from Scholl analyses, that has already been successfully applied to olfactory epithelium explants 
(Giacobini et al., 2004). Explants were stained for $\beta$ III-tubulin, as described above, to visualize the whole axon length. Using morphometric software developed by Explora Nova (France), we drew concentric arcs centered on the explant and separated by $100 \mu \mathrm{m}$ (as shown in Supplementary Fig.2A). Axonal length $(\mu \mathrm{m})$ was defined as the distance reached by the five longest axons emerging from the explant. This procedure was used because the dense network of axons emerging from the explant did not allow us to systematically follow individual axons along their whole length. In addition, we measured the surface occupied by the network of axons and expressed this parameter according to the surface of the explant (ratio axonal surface/explant surface). The results are obtained from three experiments, using a total of $11 \mathrm{WT}$ and $8 \mathrm{STOP}^{-/-}$embryos from four different litters. When several explants were obtained from the same embryo, the value for this embryo corresponds to the mean of these explants. Statistical analyses of the results were processed by paired bilateral Student ttests.

\section{Quantitative histological analysis}

We studied the organization of the olfactory bulb in $\mathrm{STOP}^{-/}$mice by conducting a morphometric analysis of the glomerular and the olfactory nerve layers, completed with a focus on the glomerular compartmentalization. This analysis was done at postnatal stages P6, P19 and in adult animals ( 8 weeks), with 3 animals per age and per genotype.

\section{Morphometric analysis}

Using the morphometric software from the Explora Nova company (France), we determined the number and diameter of the glomeruli in olfactory bulb sections as well as the total glomerular surface (20X magnification) stained with Crezyl Violet (0.5\%o in water and $0.3 \%$ glacial acetic acid) (see Supplementary Fig.2B). All glomeruli in the section were analyzed (about 70 glomeruli per section for an adult olfactory bulb and 40 for P6 bulb). The 
perimeter of the External Plexiform Layer (EPL) was also measured and used to normalize the number of glomeruli and the total glomerular surface such that both were expressed as a ratio per $\mu \mathrm{m}$ of EPL. Using the same software, we also determined the relative thickness of the inner and the outer parts of the olfactory nerve layer on sections immunostained for peripherin (20X magnification), a component of the intermediate filament which is restricted to the oONL (Akins and Greer, 2006a). The value presented for each animal is the mean obtained from the left and right olfactory bulbs, each one analyzed on four sections separated by $56 \mu \mathrm{m}$ (total of 8 sections) and chosen at a similar position on the anteroposterior axis.

The epithelial thickness was measured on coronal sections of the nasal cavity stained with Crezyl Violet by drawing lines perpendicular to the basal lamina on the olfactory epithelium lining the nasal septum. This was done on both sides of the septum (20X magnification), 4 lines per side and on 4 sections per animal, such that the value given for each animal is the mean of 32 measurements.

\section{Axonal convergence analysis}

In order to analyze the convergence of subpopulations of olfactory axons expressing the same molecular odorant receptor, we immunostained serial sections of adult olfactory bulb with the anti-mOR256-17 and anti-mOR28 antibodies (3 animals per genotype). Sections were sampled every $56 \mu \mathrm{m}$ ( 1 out of every $414 \mu \mathrm{m}$-thick sections). For mOR256-17, stained sections spanned $200 \mu \mathrm{m}$ before and after the presumed position of the target glomerulus. For mOR28, we stained the whole olfactory bulb along its entire anteroposterior axis.

\section{Glomerular organization analysis}

In order to analyze the intraglomerular compartmentalization, we quantified the distribution of several markers specific for each compartment in the glomeruli. For the axonal compartment, we used GAP43 and OMP, the respective markers of the immature and mature olfactory axons. For the dendritic compartment, the specific marker MAP2 was chosen. We 
also stained for synaptophysin, a ubiquitous presynaptic vesicle marker, and for VGluT1 and VGluT2 which are the vesicular glutamate transporters specifically expressed in the presynaptic specializations of mitral/tufted cells dendrites and OSN axon terminals respectively. Sections from animals of the same age (three animals per genotype) were processed for immunohistochemistry in the same experimental set. Two pictures were randomly taken in each of the four quadrants of the olfactory bulb (dorsal, ventral, medial and lateral) using the same exposure parameters (40X magnification and same exposure timing). A detection threshold was set for each marker with an image analysis software (MorphoExpert or MetaMorph Offline v6.3) and kept identical throughout the analysis for animals of the same age. Using this software, we measured the labeled surface which is expressed as a percentage of the glomerular surface. The value presented for each group is a mean from several sections that were sampled as described above for the morphological analysis.

Statistical analysis of the results was done by ANOVA and Bonferroni post-hoc test to study the effect of age in each genotype and by bilateral paired Student t-test in order to compare wild type and STOP-null mice at each developmental stage. The use of one or the other methodology is specified in the figure legends. 


\section{FIGURE LEGENDS}

\section{Figure 1: E-STOP protein expression in the developing rat olfactory system.}

(A-B) During early embryonic development, E-STOP-immunoreactive olfactory sensory neuron axons (arrows) emerge from the olfactory epithelium (OE) and aggregate into the presumptive olfactory nerve layer (pONL), as shown at E14 (A) and E16 (B). (C-C') At birth, both olfactory (arrow in C) and vomeronasal axon fascicles (arrowhead in C') display a sustained labeling while coursing through the lamina propria. (D) A moderate E-STOP staining persisted in olfactory axon bundles in adult (arrow). (E-G) The olfactory nerve layer is the most immunoreactive layer of the olfactory bulb during late embryonic development, as shown at E18 (E). After birth, the olfactory nerve layer displays a heterogeneous staining, since the labeling intensity is stronger in the outer part (oONL) than in the inner part (iONL) in newborn pups $(\mathrm{F})$ as well as in adult animals $(\mathrm{G})$.

Gr: Granule cell layer, IPL: Internal Plexiform Layer, (p)Gl: (presumptive) Glomerular layer, Mi: Mitral cell layer, Tel: Telencephalon, VNO: Vomeronasal Organ.

Scale bar $=50 \mu \mathrm{m}$ in A-C and G; $100 \mu \mathrm{m}$ in $\mathrm{C}^{\prime}$ and D-F.

\section{Figure 2: N-STOP protein expression in the developing rat olfactory system.}

(A) N-STOP protein is not detected at embryonic stage E14. (B-C) At P6 and in adult, olfactory sensory neuron axons coursing through the lamina propria (LP) display N-STOPimmunoreactivity. Non-specific staining in the connective tissue is also detected when the primary antibody is omitted on adjacent control sections (C'). (D-F) In the postnatal olfactory bulb (P6, P15 and adult), N-STOP is heterogeneously distributed in the olfactory nerve layer (ONL), since the staining appears stronger in the inner part (iONL) than in the outer part (oONL).

EPL: External Plexiform Layer, Gr: Granule cell layer, Gl: Glomerular Layer, Mi: Mitral cell layer, OE: Olfactory Epithelium, (p)ONL: (presumptive) Olfactory Nerve Layer, Tel: Telencephalon. 
Scale bar $=50 \mu \mathrm{m}$ in A-C; $100 \mu \mathrm{m}$ in $\mathrm{D} ; 200 \mu \mathrm{m}$ in $\mathrm{E}$ and $\mathrm{F}$.

Figure 3: Isoform specific gradient distribution of STOP proteins in the olfactory nerve layer at P6

(A-F) GFAP $^{+}$glial processes are restricted to the glomerular layer $(\mathrm{Gl})$ and the inner part of the olfactory nerve layer (iONL). Their presence allows to clearly delimit the iONL from the outer part of the olfactory nerve layer (oONL). (A-C) Immunoreactivity for N-STOP is more intense in the iONL than in the oONL. (D-F) E-STOP-immunolabelling is absent from the iONL, while the oONL is strongly stained. Note that variations in the intensity of GFAP staining are due to the use of two different antibodies (one monoclonal and one polyclonal) to allow simultaneous staining with alphaE (E-STOP) and 175 (N-STOP) antibodies respectively. (G-I) Immunoreactivity for N-STOP is more intense in the iONL than in the oONL. Since the iONL is devoid of E-STOP-staining, it appears clearly green-colored on the merged image.

Scale bar $=100 \mu \mathrm{m}$

\section{Figure 4: Subcellular localization of STOP protein in the olfactory axons in vitro.}

(A) Olfactory epithelium explants develop a dense network of STOP-immunoreactive axons after 4 days in vitro (23C antibody). (B) STOP-immunoreactivity is distributed along the axonal shaft and present in axonal varicosities (arrows). (C-E) STOP protein is enriched in the central domain of the axonal growth cone, (arrows). It is also detected in some filopodia (arrowheads) and in the leading fringe of the lamelipodium, where it colocalizes with actin. Note that the thinnest filopodium displays actin staining but is devoid of STOP-labeling (asterisk).

Scale bar $=50 \mu \mathrm{m}$ in $\mathrm{A}, 20 \mu \mathrm{m}$ in $\mathrm{B}, 5 \mu \mathrm{m}$ in $\mathrm{C}$-E. 


\section{Figure 5: In vitro outgrowth ability of $\mathrm{STOP}^{-/-}$olfactory axons.}

(A) Examples of the maps used to quantify axon outgrowth from wild type $(+/+)$ and STOPnull (-/-) embryonic olfactory epithelium explants. (B) No significant difference in axonal length is detected between genotypes. (C) The ratio axonal surface/explant surface is higher in wild type compared to STOP-null explants. Results are expressed as mean \pm s.e.m, $n=11$ for $\mathrm{STOP}^{+/+}$explants and $\mathrm{n}=7$ for $\mathrm{STOP}^{-/-}$explants. Paired bilateral t-test was used to compare genotypes.

$* \mathrm{p} \leq 0.05$.

\section{Figure 6: In situ morphometrical analysis of $\mathrm{STOP}^{-/-}$mice olfactory system}

The mean glomerular diameter (A), the number of glomeruli (B) and the total glomerular surface (C) increase during postnatal development for both wild type (+/+) and STOP-null (-/) animals. Statistical analysis was done by ANOVA and Bonferroni post-hoc test which significance is represented by asterisks (*) for STOP-null mice and by pound signs (\#) for wild type animals. (D) Comparison of wild type and STOP-null mice at P6 and in adult, two key developmental stages. Statistical analysis was done by paired bilateral Student t-test. Adult $\mathrm{STOP}^{-/}$glomeruli are smaller $(\mathrm{p}=0.007)$ but more numerous than wild type glomeruli $(\mathrm{p}=0.03)$. No significant difference was detected for the total glomerular surface, as well as the olfactory epithelium thickness at any stage. Results are presented as mean \pm s.e.m, $n=3$ animals per genotype and per age.

*** or \#\#\# $\mathrm{p} \leq 0.005, * *$ or \#\# $\mathrm{p} \leq 0.01, *$ or $\# \mathrm{p} \leq 0.05$

ad: adult; EPL: External Plexiform Layer.

Figure 7: Regionalization of the olfactory nerve layer in the developing STOP $^{-/-}$olfactory bulb. 
(A) Peripherin is distributed in WT controls $(+/+)$ following a decreasing gradient in the olfactory nerve layer (ONL) at P6 (A1) and in adult (A3). The subdivision of the ONL in outer (oONL) and inner (iONL) regions is maintained in STOP-null olfactory bulbs (A2 and A4, -/-). (B) Quantitative analysis of the relative thickness of the inner and outer parts of the olfactory nerve layer. Results are expressed in percent of the thickness of the total olfactory nerve layer \pm s.e.m, $\mathrm{n}=3$ animals per genotype and per age. No significant difference was detected by Student t-test between genotypes, whatever the developmental stage considered. Gl: Glomerular layer, VN: Vomeronasal Nerve. Scale bar $=50 \mu \mathrm{m}$.

Figure 8: Olfactory axon convergence in the olfactory bulb of adult STOP ${ }^{-/}$mice.

mOR28 immunoreactive axons converge on two glomeruli located in the same ventrolateral and ventromedial positions in adult wild type $(\mathrm{A}, \mathrm{C},+/+)$ and STOP-null mice olfactory bulbs (B, D, -/-). Convergence on a single locus is visible at higher magnification for both genotypes (A'-D'). mOR256-17 immunoreactive axons also converge on a glomerulus located at a similar position in the medial region of the posterior olfactory bulb in adult wild type (E) and STOP-null mice (F).

Scale bar $=400 \mu \mathrm{m}$ in A-D, $50 \mu \mathrm{m}$ in A'-D' and $25 \mu \mathrm{m}$ in E-F.

Figure 9: Glomerular compartmentalization in the developing olfactory bulb of STOP${ }^{-/-}$ mice.

(A) At P6, the GAP43- and OMP-immunoreactive surfaces are wider in STOP-null mice (-/-) than in wild type animals $(+/+)$. An example of the glomerular GAP43-staining at P6 is shown in A'. (B) In adults, only the synaptophysin-positive surface is higher in mutants compared to wild type. An example of the glomerular synaptophysin-staining in adult is shown in B'. Results are expressed as the percent of the glomerular surface that is immunoreactive and 
presented in mean \pm s.e.m, $n=3$ animals per genotype and per age. Paired bilateral t-test was used to compare genotypes at each age. Note that because of the thickness of the sections (it is not a confocal picture), the sum of the percentage represented by axonal and dendritic compartments may be superior to $100 \%$.

$* * * \mathrm{p} \leq 0.005, * * \mathrm{p} \leq 0.01, * \mathrm{p} \leq 0.05$.

Scale bar $=50 \mu \mathrm{m}$.

\section{Supplementary Figure 1: Gross morphology of STOP ${ }^{-/-}$mice olfactory system}

(A) At embryonic stage E15, GAP43-staining does not reveal any large alterations of the morphology of the olfactory system in STOP-null mice (-/-), compared to wild type $(+/+)$. GAP43-immunopositive axons emerge from the olfactory epithelium (OE), fascicle in the lamina propria (arrowhead) and contact the developing olfactory bulb (OB), forming the olfactory nerve layer (ONL). (B) At postnatal day 6 (P6), the different layers of the olfactory bulb have developed in both genotypes. At higher magnification, GAP43 and OMP stainings reveal the formation of glomeruli (arrows) in the olfactory bulb of both genotypes.

Scale bar $=200 \mu \mathrm{m}$.

VNO: Vomeronasal Organ.

\section{Supplementary Figure 2: Quantitative morphometry methods}

(A) Quantification of in vitro axon outgrowth using a method modified from Sholl analysis. $100 \mu \mathrm{m}$-spaced concentric arc are drawn and centered on the explant. The length of the five longest axons is considered as the axonal length for an explant (in $\mu \mathrm{m})$. The surface covered by the axons is also measured and expressed according to the surface of the explant (ratio axonal surface/explant surface). (B) Method of the morphometrical analysis of olfactory bulb sections. Example of a map used to count the number of glomeruli and measure their mean 
diameter as well as the perimeter of the External Plexiform Layer (EPL) in an adult olfactory bulb section (drawn with Explora Nova software).

\section{Supplementary Figure 3: Convergence of mOR28 olfactory axons in adult STOP ${ }^{-/-}$mice}

Serial sections along the entire anteroposterior axis of the whole olfactory bulb were stained for mOR28 (see material and methods for details about the sampling of the sections). Only sections near the position of the target glomeruli are shown in this figure. The distance from the first section is indicated in the bottom left corner. Only two glomeruli were found in each whole olfactory bulb of adult wild type (+/+) and STOP-null (-/-) mice. (A and B) The first mOR28 glomerulus is located in the ventrolateral region. (C and D) The second glomerulus is positioned in the ventromedial side of the most posterior region of the olfactory bulb. Arrows mark the position of a mOR28-immunoreactive glomerulus and arrowheads point out immunopositive axons traveling in the olfactory nerve layer.

Scale bar $=400 \mu \mathrm{m}$.

\section{Supplementary Figure 4: STOP antibodies specificity}

Proteins were extracted from adult mouse olfactory bulb tissues (WT and $\mathrm{STOP}^{-/}$) in lysis buffer (50mM Tris- $\mathrm{HCl} \mathrm{pH} 7.9,120 \mathrm{mM} \mathrm{NaCl}, 0.5 \%$ NP-40, 1mM EDTA, 0.1mM NaF, $0.1 \mathrm{mM}$ Na orthovanadate, $1 \mathrm{mM}$ PMSF, $1 \mathrm{mM}$ benzamidine, $1 \mathrm{X}$ Roche protease inhibitor cocktail). $20 \mu \mathrm{g}$ of proteins were loaded and separated on a $7.5 \%$ polyacrylamide gel $(0.1 \%$ SDS) and then transferred to a PVDF membrane. Membranes were probed overnight at $4{ }^{\circ} \mathrm{C}$ with one of the different primary antibodies diluted in PBS-tween $0.15 \%$ containing $5 \%$ dry milk: 23C (rabbit, 1:5000), alphaE (rabbit, 1:3000), 175 (mouse, 1:2000), actin (mouse, Chemicon MAB1501R, 1:6000). The appropriate secondary antibody was chosen between sheep anti-mouse HRP (1:20000; Amersham) or goat anti-rabbit HRP (1:20000, Amersham) and incubated for $90 \mathrm{~min}$ at room temperature. HRP enzymatic activity was revealed using the 
Millipore chemioluminescent kit following the manufacturer's protocol. The same membrane was successively probed with $\alpha \mathrm{E}$, actin, 175 and $23 \mathrm{C}$ antibodies, by processing a stripping step between each antibody (antibody stripping buffer from Gene-Bio Application Ltd, following manufacturer's recommendations).

(A) The 23C antibody reveals that all the STOP isoforms are present in olfactory bulb extracts. The expected molecular weights of the mouse isoforms are $145 \mathrm{kDa}$ for N-STOP and $79 \mathrm{kDa}$ for E-STOP, but the apparent molecular weight may vary upon SDS-PAGE conditions (Bosc et al., 2003). Non neuronal isoforms, F-STOP (fibroblastic), A-STOP (astrocytic) and O-STOP (oligodendrocytic) are also detected but to a lesser extend, in accordance with the presence of these cell populations in the mouse olfactory bulb. (B) The $\alpha \mathrm{E}$ antibody revealed a single band corresponding to the reported molecular weight of $\mathrm{E}$ STOP in mouse brain extracts (Galiano et al., 2004). The 175 antibody revealed a single band corresponding to the well-described molecular weight of N-STOP (Bosc et al., 1996; Pirollet et al., 1989). Neither of the STOP antibodies revealed any staining in extracts from STOP ${ }^{-/-}$ mouse olfactory bulb, further confirming their specificity. (D) Actin is probed to verify the equal amount of protein loaded. 


\title{
AKNOWLEDGEMENTS
}

We thank Dr. H. Breer (University of Hohenheim, Germany) and Dr F. Margolis (University of Maryland, USA) for kindly providing mOR256-17 and OMP antibodies respectively.We are grateful to Dr. C.A. Greer (Yale University, USA) for his thorough reading of the manuscript and his numerous helpful comments. We also thank Dr R. Axel (Columbia University, USA) for providing the mOR28 antibody in collaboration with Dr C.A. Greer's lab. This study was supported by the Centre National de la Recherche Scientifique, the Université de Lyon, Lyon 1 (UMR 5020 - CNRS / UCB Lyon1) and Institut Fédératif des Neurosciences de Lyon.

\begin{abstract}
ABBREVIATIONS
BIII-tubulin: $\beta$-tubulin isotype III ; E1: Embryonic day 1 ; GAP43: Growth-Associated Protein of 43kDa ; GFAP: Glial Fibrillary Acidic Protein ; MAP: Microtubule-Associated Protein ; OB: Olfactory Bulb ; OE: Olfactory Epithelium ; OMP: Olfactory Marker Protein ; ONL: Olfactory Nerve Layer ; iONL and oONL: inner and outer Olfactory Nerve Layer ; OSN: Olfactory Sensory Neuron ; P1: Postnatal day 1 ; SCG10: Superior Cervical Ganglion protein ; STOP: Stable-Tubule Only Polypeptide ; VGluT: Vesicular Glutamate Transporter ; WT: wild type.
\end{abstract}




\section{REFERENCES}

Akins, M.R., Greer, C.A., 2006a. Cytoskeletal organization of the developing mouse olfactory nerve layer. J Comp Neurol 494, 358-367.

Akins, M.R., Greer, C.A., 2006b. Axon behavior in the olfactory nerve reflects the involvement of catenin-cadherin mediated adhesion. J Comp Neurol 499, 979-989.

Andrieux, A., Salin, P., Schweitzer, A., Begou, M., Pachoud, B., Brun, P., Gory-Faure, S., Kujala, P., Suaud-Chagny, M.F., Hofle, G., Job, D., 2006. Microtubule stabilizer ameliorates synaptic function and behavior in a mouse model for schizophrenia. Biol Psychiatry 60, 12241230 .

Andrieux, A., Salin, P.A., Vernet, M., Kujala, P., Baratier, J., Gory-Faure, S., Bosc, C., Pointu, H., Proietto, D., Schweitzer, A., Denarier, E., Klumperman, J., Job, D., 2002. The suppression of brain cold-stable microtubules in mice induces synaptic defects associated with neuroleptic-sensitive behavioral disorders. Genes Dev 16, 2350-2364.

Arnold, S.E., Han, L.Y., Moberg, P.J., Turetsky, B.I., Gur, R.E., Trojanowski, J.Q., Hahn, C.G., 2001. Dysregulation of olfactory receptor neuron lineage in schizophrenia. Arch Gen Psychiatry 58, 829-835.

Arnold, S.E., Hyman, B.T., Van Hoesen, G.W., Damasio, A.R., 1991. Some cytoarchitectural abnormalities of the entorhinal cortex in schizophrenia. Arch Gen Psychiatry 48, 625-632.

Au, W.W., Treloar, H.B., Greer, C.A., 2002. Sublaminar organization of the mouse olfactory bulb nerve layer. J Comp Neurol 446, 68-80.

Baratier, J., Peris, L., Brocard, J., Gory-Faure, S., Dufour, F., Bosc, C., Fourest-Lieuvin, A., Blanchoin, L., Salin, P., Job, D., Andrieux, A., 2006. Phosphorylation of microtubuleassociated protein STOP by calmodulin kinase II. J Biol Chem 281, 19561-19569.

Begou, M., Brun, P., Bertrand, J.B., Job, D., Schweitzer, A., D'Amato, T., Saoud, M., Andrieux, A., Suaud-Chagny, M.F., 2007. Post-pubertal emergence of alterations in locomotor activity in stop null mice. Synapse 61, 689-697.

Biffo, S., Goren, T., Khew-Goodall, Y.S., Miara, J., Margolis, F.L., 1991. Expression of calmodulin mRNA in rat olfactory neuroepithelium. Brain Res Mol Brain Res 10, 13-21.

Bosc, C., Andrieux, A., Job, D., 2003. STOP proteins. Biochemistry 42, 12125-12132.

Bosc, C., Cronk, J.D., Pirollet, F., Watterson, D.M., Haiech, J., Job, D., Margolis, R.L., 1996. Cloning, expression, and properties of the microtubule-stabilizing protein STOP. Proc Natl Acad Sci U S A 93, 2125-2130.

Bouquet, C., Soares, S., von Boxberg, Y., Ravaille-Veron, M., Propst, F., Nothias, F., 2004. Microtubule-associated protein 1B controls directionality of growth cone migration and axonal branching in regeneration of adult dorsal root ganglia neurons. J Neurosci 24, 72047213. 
Bouvrais-Veret, C., Weiss, S., Hanoun, N., Andrieux, A., Schweitzer, A., Job, D., Hamon, M., Giros, B., Martres, M.P., 2008. Microtubule-associated STOP protein deletion triggers restricted changes in dopaminergic neurotransmission. J Neurochem 104, 745-756.

Brun, P., Begou, M., Andrieux, A., Mouly-Badina, L., Clerget, M., Schweitzer, A., Scarna, H., Renaud, B., Job, D., Suaud-Chagny, M.F., 2005. Dopaminergic transmission in STOP null mice. J Neurochem 94, 63-73.

Camoletto, P., Colesanti, A., Ozon, S., Sobel, A., Fasolo, A., 2001. Expression of stathmin and SCG10 proteins in the olfactory neurogenesis during development and after lesion in the adulthood. Brain Res Bull 54, 19-28.

Chien, C.L., Lee, T.H., Lu, K.S., 1998. Distribution of neuronal intermediate filament proteins in the developing mouse olfactory system. J Neurosci Res 54, 353-363.

Couegnas, A., Schweitzer, A., Andrieux, A., Ghandour, M.S., Boehm, N., 2007. Expression pattern of stop lacZ reporter gene in adult and developing mouse brain. J Neurosci Res 85, 1515-1527.

Dent, E.W., Gertler, F.B., 2003. Cytoskeletal dynamics and transport in growth cone motility and axon guidance. Neuron 40, 209-227.

Dillon, C., Goda, Y., 2005. The actin cytoskeleton: integrating form and function at the synapse. Annu Rev Neurosci 28, 25-55.

Dixit, R., Ross, J.L., Goldman, Y.E., Holzbaur, E.L., 2008. Differential regulation of dynein and kinesin motor proteins by tau. Science 319, 1086-1089.

Eastwood, S.L., Lyon, L., George, L., Andrieux, A., Job, D., Harrison, P.J., 2007. Altered expression of synaptic protein mRNAs in STOP (MAP6) mutant mice. J Psychopharmacol $21,635-644$.

Ennis, M., Linster, C., Aroniadou-Anderjaska, V., Ciombor, K., Shipley, M.T., 1998.

Glutamate and synaptic plasticity at mammalian primary olfactory synapses. Ann N Y Acad Sci 855, 457-466.

Farbman, A.I., Margolis, F.L., 1980. Olfactory marker protein during ontogeny: immunohistochemical localization. Dev Biol 74, 205-215.

Feron, F., Perry, C., Hirning, M.H., McGrath, J., Mackay-Sim, A., 1999. Altered adhesion, proliferation and death in neural cultures from adults with schizophrenia. Schizophr Res 40, 211-218.

Gabellec, M.M., Panzanelli, P., Sassoe-Pognetto, M., Lledo, P.M., 2007. Synapse-specific localization of vesicular glutamate transporters in the rat olfactory bulb. Eur J Neurosci 25, 1373-1383.

Galiano, M.R., Bosc, C., Schweitzer, A., Andrieux, A., Job, D., Hallak, M.E., 2004.

Astrocytes and oligodendrocytes express different STOP protein isoforms. J Neurosci Res 78, 329-337. 
Giacobini, P., Kopin, A.S., Beart, P.M., Mercer, L.D., Fasolo, A., Wray, S., 2004.

Cholecystokinin modulates migration of gonadotropin-releasing hormone-1 neurons. J Neurosci 24, 4737-4748.

Gorham, J.D., Ziff, E.B., Baker, H., 1991. Differential spatial and temporal expression of two type III intermediate filament proteins in olfactory receptor neurons. Neuron 7, 485-497.

Gory-Faure, S., Windscheid, V., Bosc, C., Peris, L., Proietto, D., Franck, R., Denarier, E., Job, D., Andrieux, A., 2006. STOP-like protein 21 is a novel member of the STOP family, revealing a Golgi localization of STOP proteins. J Biol Chem 281, 28387-28396.

Guillaud, L., Bosc, C., Fourest-Lieuvin, A., Denarier, E., Pirollet, F., Lafanechere, L., Job, D., 1998. STOP proteins are responsible for the high degree of microtubule stabilization observed in neuronal cells. J Cell Biol 142, 167-179.

Hisaoka, T., Morikawa, Y., Kitamura, T., Senba, E., 2004. Expression of a member of tumor necrosis factor receptor superfamily, TROY, in the developing olfactory system. Glia 45, 313324.

Job, D., Fischer, E.H., Margolis, R.L., 1981. Rapid disassembly of cold-stable microtubules by calmodulin. Proc Natl Acad Sci U S A 78, 4679-4682.

Johnson, B.A., Woo, C.C., Ninomiya-Tsuboi, K., Leon, M., 1996. Synaptophysin-like immunoreactivity in the rat olfactory bulb during postnatal development and after restricted early olfactory experience. Brain Res Dev Brain Res 92, 24-30.

Kasowski, H.J., Kim, H., Greer, C.A., 1999. Compartmental organization of the olfactory bulb glomerulus. J Comp Neurol 407, 261-274.

Kim, H., Greer, C.A., 2000. The emergence of compartmental organization in olfactory bulb glomeruli during postnatal development. J Comp Neurol 422, 297-311.

Klenoff, J.R., Greer, C.A., 1998. Postnatal development of olfactory receptor cell axonal arbors. J Comp Neurol 390, 256-267.

Luo, L., Flanagan, J.G., 2007. Development of continuous and discrete neural maps. Neuron 56, 284-300.

McCurdy, R.D., Feron, F., Perry, C., Chant, D.C., McLean, D., Matigian, N., Hayward, N.K., McGrath, J.J., Mackay-Sim, A., 2006. Cell cycle alterations in biopsied olfactory neuroepithelium in schizophrenia and bipolar I disorder using cell culture and gene expression analyses. Schizophr Res 82, 163-173.

McLean, I.W., Nakane, P.K., 1974. Periodate-lysine-paraformaldehyde fixative. A new fixation for immunoelectron microscopy. J Histochem Cytochem 22, 1077-1083.

Moberg, P.J., Agrin, R., Gur, R.E., Gur, R.C., Turetsky, B.I., Doty, R.L., 1999. Olfactory dysfunction in schizophrenia: a qualitative and quantitative review.

Neuropsychopharmacology 21, 325-340. 
Mombaerts, P., 2006. Axonal wiring in the mouse olfactory system. Annu Rev Cell Dev Biol $22,713-737$.

Nakamura, K., Hioki, H., Fujiyama, F., Kaneko, T., 2005. Postnatal changes of vesicular glutamate transporter (VGluT) 1 and VGluT2 immunoreactivities and their colocalization in the mouse forebrain. J Comp Neurol 492, 263-288.

Owen, M.J., O'Donovan, M.C., Harrison, P.J., 2005. Schizophrenia: a genetic disorder of the synapse? Bmj 330, 158-159.

Pellier-Monnin, V., Astic, L., Bichet, S., Riederer, B.M., Grenningloh, G., 2001. Expression of SCG10 and stathmin proteins in the rat olfactory system during development and axonal regeneration. J Comp Neurol 433, 239-254.

Pirollet, F., Derancourt, J., Haiech, J., Job, D., Margolis, R.L., 1992. Ca(2+)-calmodulin regulated effectors of microtubule stability in bovine brain. Biochemistry 31, 8849-8855.

Pirollet, F., Rauch, C.T., Job, D., Margolis, R.L., 1989. Monoclonal antibody to microtubuleassociated STOP protein: affinity purification of neuronal STOP activity and comparison of antigen with activity in neuronal and nonneuronal cell extracts. Biochemistry 28, 835-842.

Powell, K.J., Hori, S.E., Leslie, R., Andrieux, A., Schellinck, H., Thorne, M., Robertson, G.S., 2007. Cognitive impairments in the STOP null mouse model of schizophrenia. Behav Neurosci 121, 826-835.

Richard, M., Giannetti, N., Saucier, D., Sacquet, J., Jourdan, F., Pellier-Monnin, V., 2005. Neuronal expression of Nogo-A mRNA and protein during neurite outgrowth in the developing rat olfactory system. Eur J Neurosci 22, 2145-2158.

Rioux, L., Gelber, E.I., Parand, L., Kazi, H.A., Yeh, J., Wintering, R., Bilker, W., Arnold, S.E., 2005. Characterization of olfactory bulb glomeruli in schizophrenia. Schizophr Res 77, 229-239.

Rioux, L., Ruscheinsky, D., Arnold, S.E., 2004. Microtubule-associated protein MAP2 expression in olfactory bulb in schizophrenia. Psychiatry Res 128, 1-7.

Schaefer, M.L., Finger, T.E., Restrepo, D., 2001. Variability of position of the P2 glomerulus within a map of the mouse olfactory bulb. J Comp Neurol 436, 351-362.

Schoenfeld, T.A., McKerracher, L., Obar, R., Vallee, R.B., 1989. MAP 1A and MAP 1B are structurally related microtubule associated proteins with distinct developmental patterns in the CNS. J Neurosci 9, 1712-1730.

Shimizu, H., Iwayama, Y., Yamada, K., Toyota, T., Minabe, Y., Nakamura, K., Nakajima, M., Hattori, E., Mori, N., Osumi, N., Yoshikawa, T., 2006. Genetic and expression analyses of the STOP (MAP6) gene in schizophrenia. Schizophr Res 84, 244-252.

Smutzer, G., Lee, V.M., Trojanowski, J.Q., Arnold, S.E., 1998. Human olfactory mucosa in schizophrenia. Ann Otol Rhinol Laryngol 107, 349-355. 
Strotmann, J., Breer, H., 2006. Formation of glomerular maps in the olfactory system. Semin Cell Dev Biol 17, 402-410.

Strotmann, J., Conzelmann, S., Beck, A., Feinstein, P., Breer, H., Mombaerts, P., 2000. Local permutations in the glomerular array of the mouse olfactory bulb. J Neurosci 20, 6927-6938.

Strotmann, J., Levai, O., Fleischer, J., Schwarzenbacher, K., Breer, H., 2004. Olfactory receptor proteins in axonal processes of chemosensory neurons. J Neurosci 24, 7754-7761.

Treloar, H.B., Feinstein, P., Mombaerts, P., Greer, C.A., 2002. Specificity of glomerular targeting by olfactory sensory axons. J Neurosci 22, 2469-2477.

Tsuboi, A., Yoshihara, S., Yamazaki, N., Kasai, H., Asai-Tsuboi, H., Komatsu, M., Serizawa, S., Ishii, T., Matsuda, Y., Nagawa, F., Sakano, H., 1999. Olfactory neurons expressing closely linked and homologous odorant receptor genes tend to project their axons to neighboring glomeruli on the olfactory bulb. J Neurosci 19, 8409-8418.

Turetsky, B.I., Moberg, P.J., Roalf, D.R., Arnold, S.E., Gur, R.E., 2003. Decrements in volume of anterior ventromedial temporal lobe and olfactory dysfunction in schizophrenia. Arch Gen Psychiatry 60, 1193-1200.

Turetsky, B.I., Moberg, P.J., Yousem, D.M., Doty, R.L., Arnold, S.E., Gur, R.E., 2000. Reduced olfactory bulb volume in patients with schizophrenia. Am J Psychiatry 157, 828-830.

Ubink, R., Halasz, N., Zhang, X., Dagerlind, A., Hokfelt, T., 1994. Neuropeptide tyrosine is expressed in ensheathing cells around the olfactory nerves in the rat olfactory bulb. Neuroscience 60, 709-726.

Ubink, R., Hokfelt, T., 2000. Expression of neuropeptide Y in olfactory ensheathing cells during prenatal development. J Comp Neurol 423, 13-25.

Vershinin, M., Carter, B.C., Razafsky, D.S., King, S.J., Gross, S.P., 2007. Multiple-motor based transport and its regulation by Tau. Proc Natl Acad Sci U S A 104, 87-92.

Viereck, C., Tucker, R.P., Matus, A., 1989. The adult rat olfactory system expresses microtubule-associated proteins found in the developing brain. J Neurosci 9, 3547-3557.

Walz, A., Mombaerts, P., Greer, C.A., Treloar, H.B., 2006. Disrupted compartmental organization of axons and dendrites within olfactory glomeruli of mice deficient in the olfactory cell adhesion molecule, OCAM. Mol Cell Neurosci 32, 1-14.

Wei, J., Zhao, A.Z., Chan, G.C., Baker, L.P., Impey, S., Beavo, J.A., Storm, D.R., 1998. Phosphorylation and inhibition of olfactory adenylyl cyclase by CaM kinase II in Neurons: a mechanism for attenuation of olfactory signals. Neuron 21, 495-504.

Wright, I.C., Rabe-Hesketh, S., Woodruff, P.W., David, A.S., Murray, R.M., Bullmore, E.T., 2000. Meta-analysis of regional brain volumes in schizophrenia. Am J Psychiatry 157, 16-25. 
Click here to download high resolution image

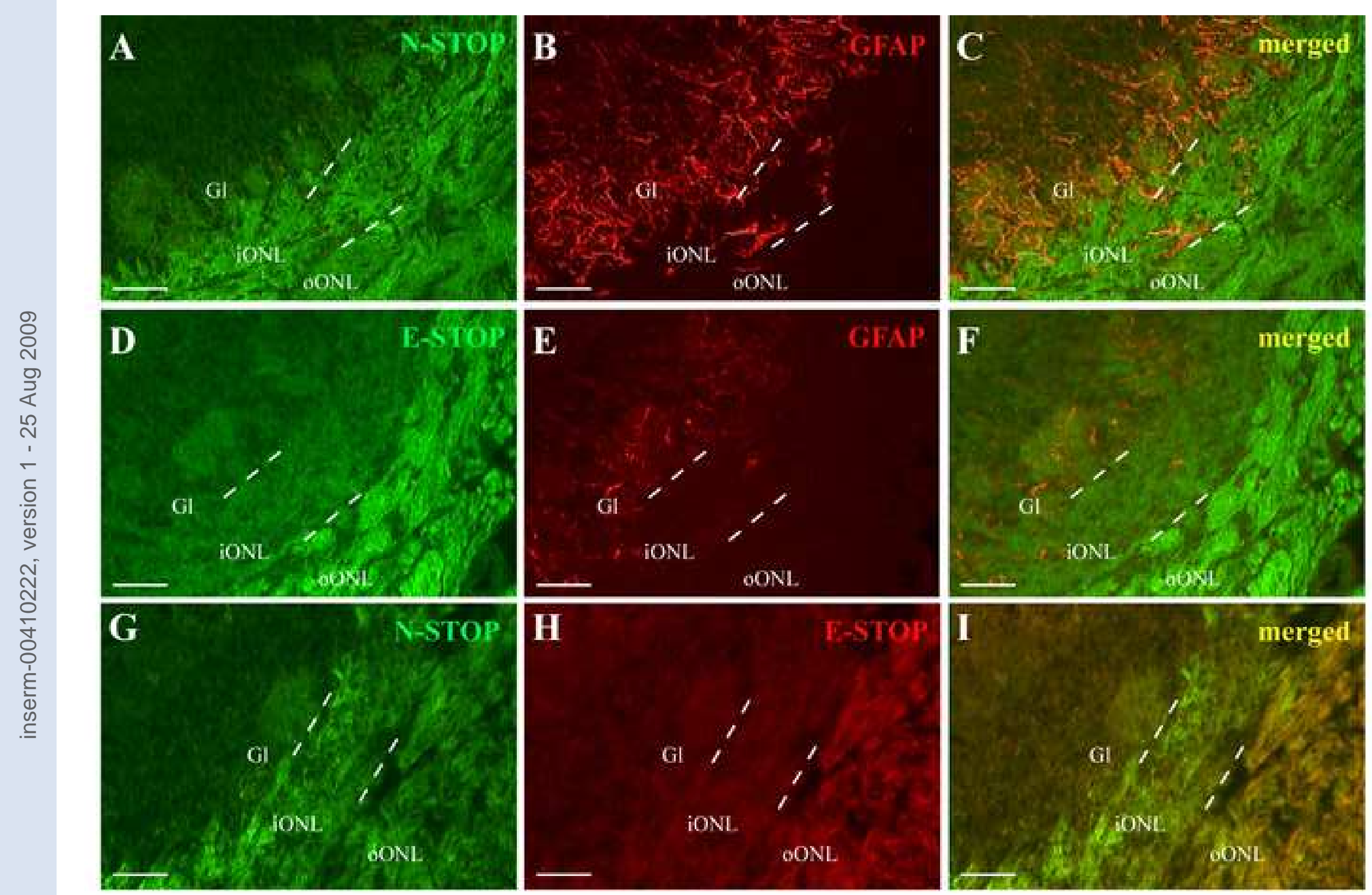

Figure 3 
Click here to download high resolution image

A
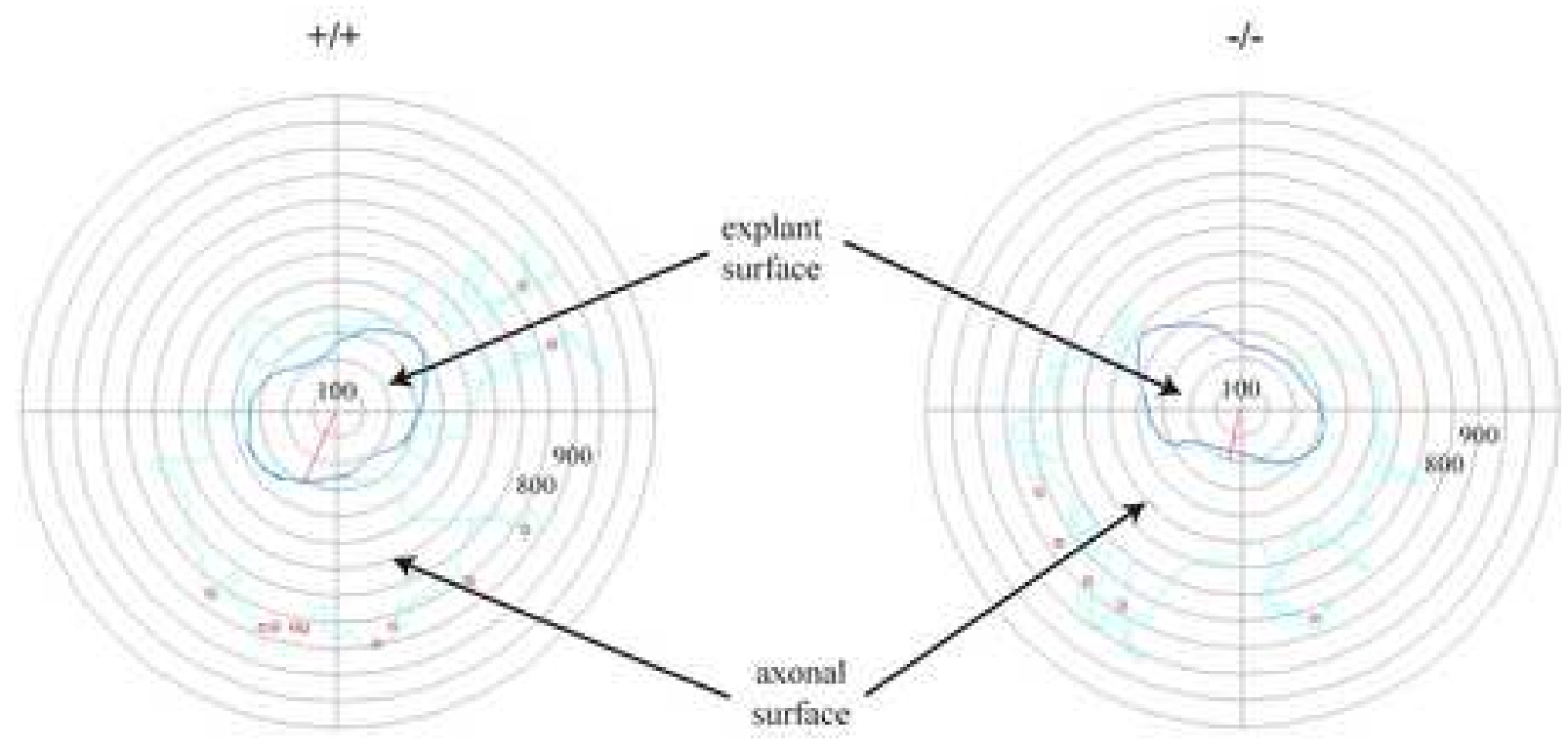

B

\section{Length ( $\mu \mathrm{m})$}

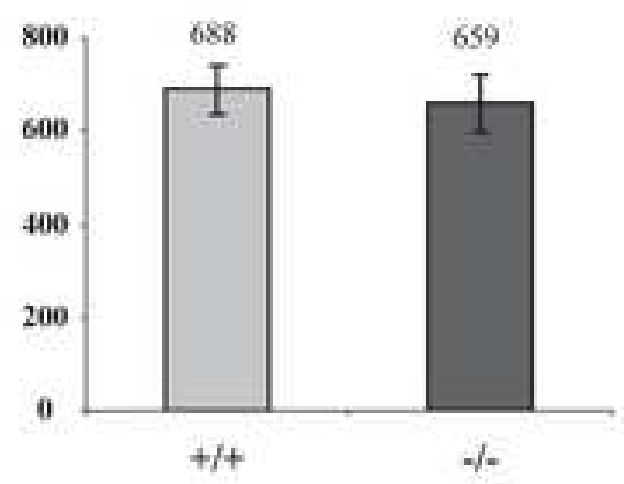

C

Surface ratio

(axonal surface/ explant surface)

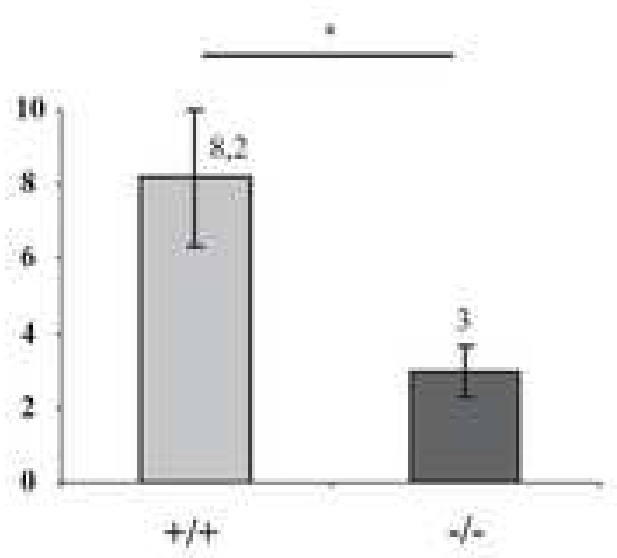

Figure 5 
A Glomerular diameter ( $\mu \mathrm{m})$

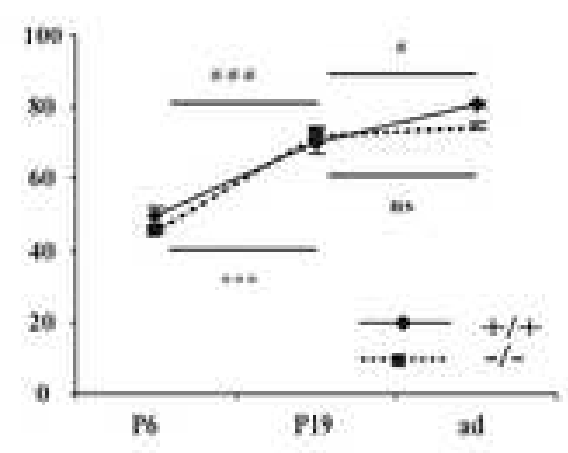

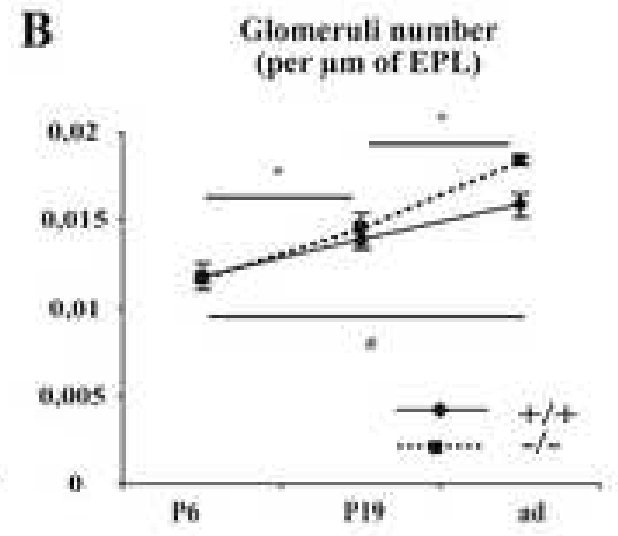

D

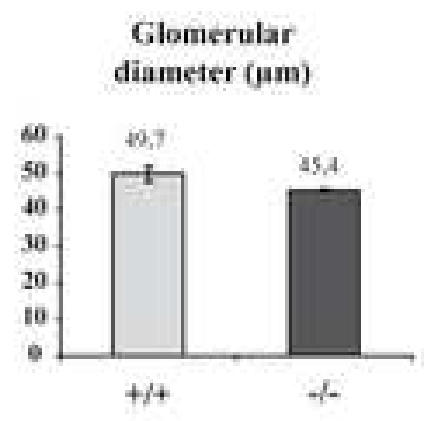

Glomerular diameter ( $\mu \mathrm{m})$

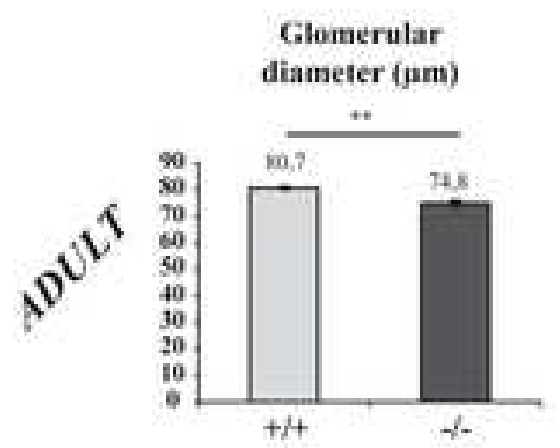

Glomeruli number (per $\mu \mathrm{m}$ of EPL)

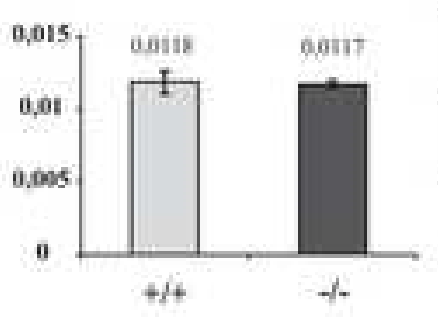

Glomeruli number (per pm of EPL)

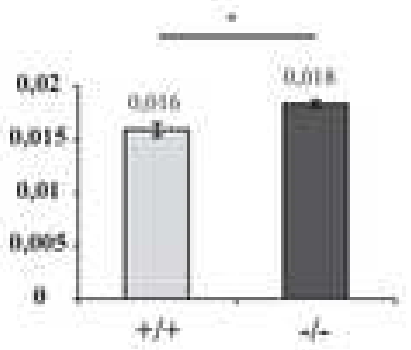

Total glomerular surface
$(\mu \mathrm{m} 2$ per $\mu \mathrm{m}$ of EPL.)

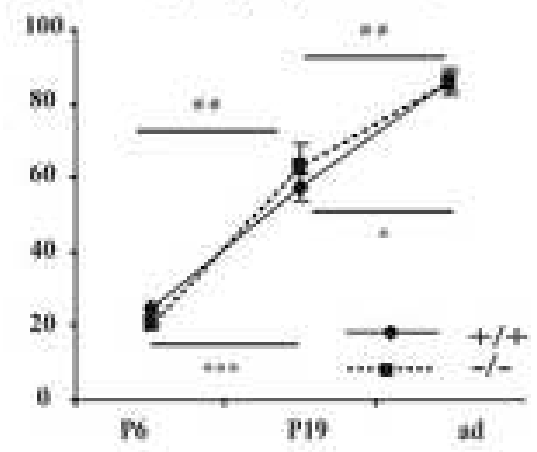

Total glomerular surface $(\mu \mathrm{m} 2$ per $\mu \mathrm{m}$ of EPL)

Olfactory epitheliam thickness ( $\mu \mathrm{m})$
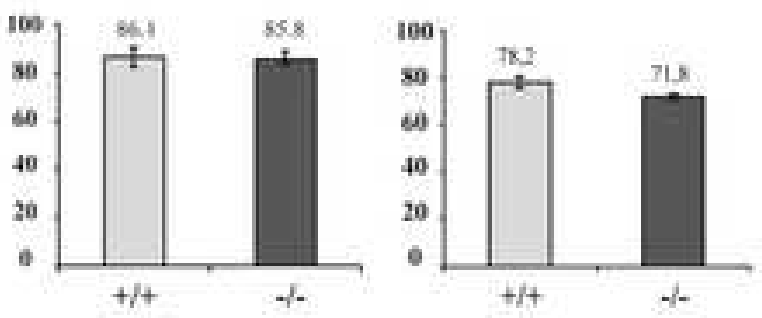

Figure 6 
A

P6

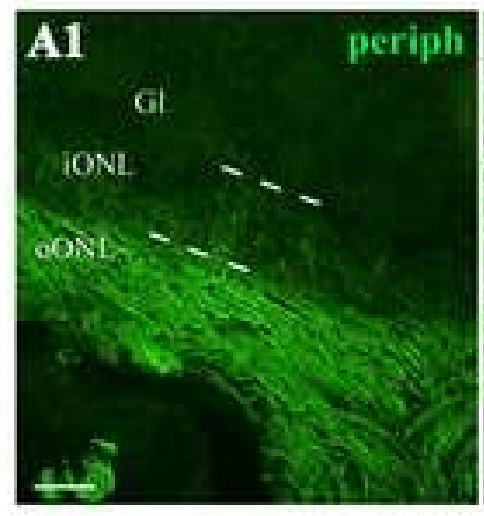

$+1+$

B

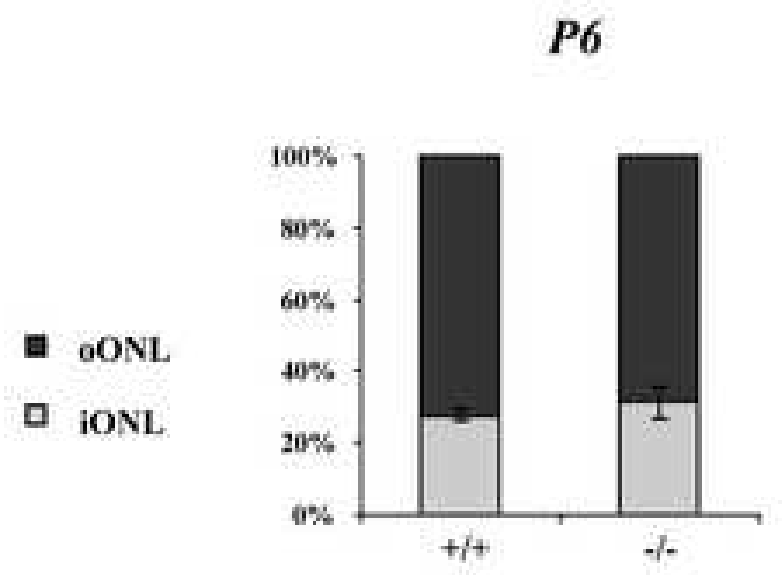

ADULT

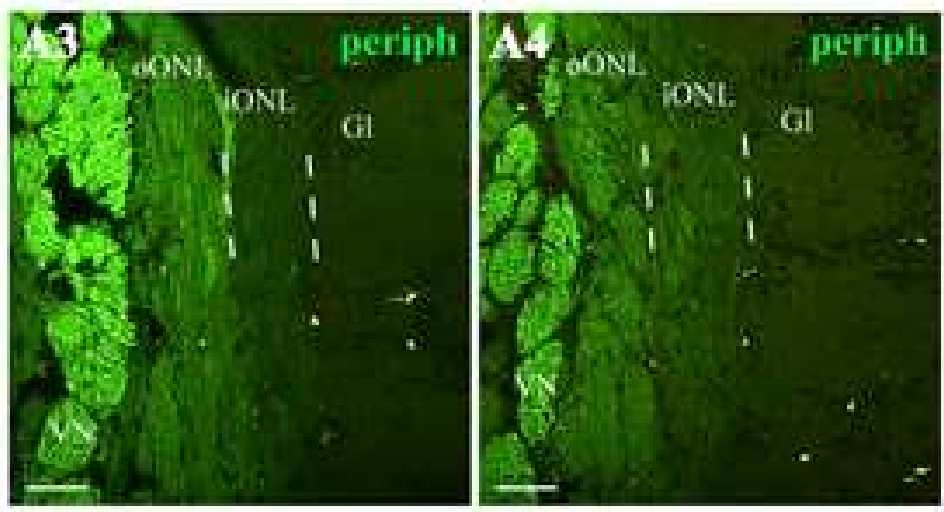

$+/+$

$-1$

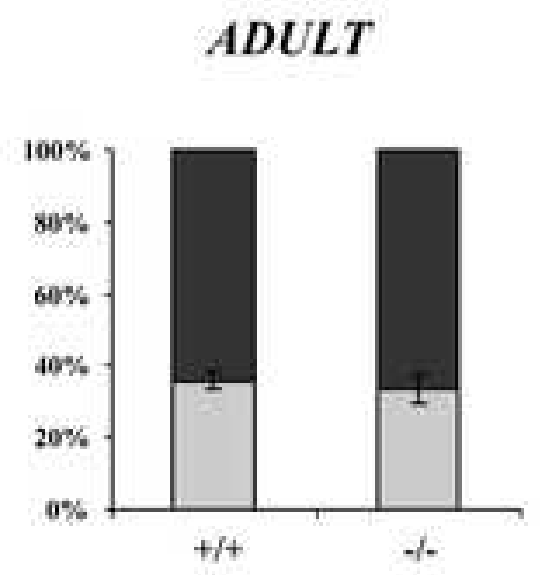

Figure 7 


\section{Figure 8}

Click here to download high resolution image

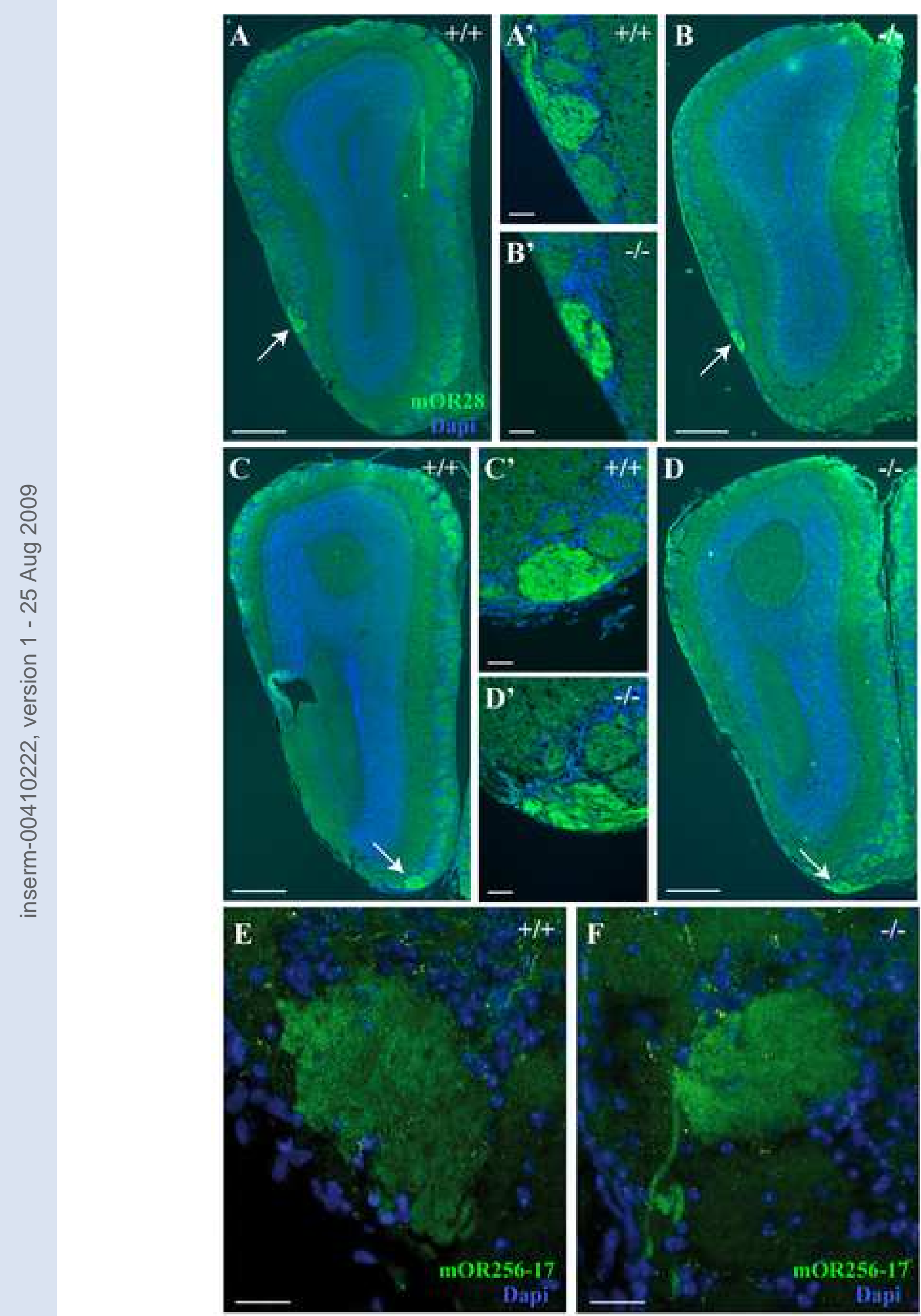

Figure 8 
A

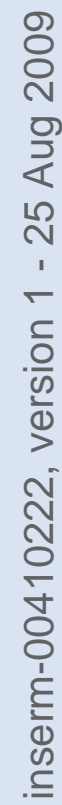

B

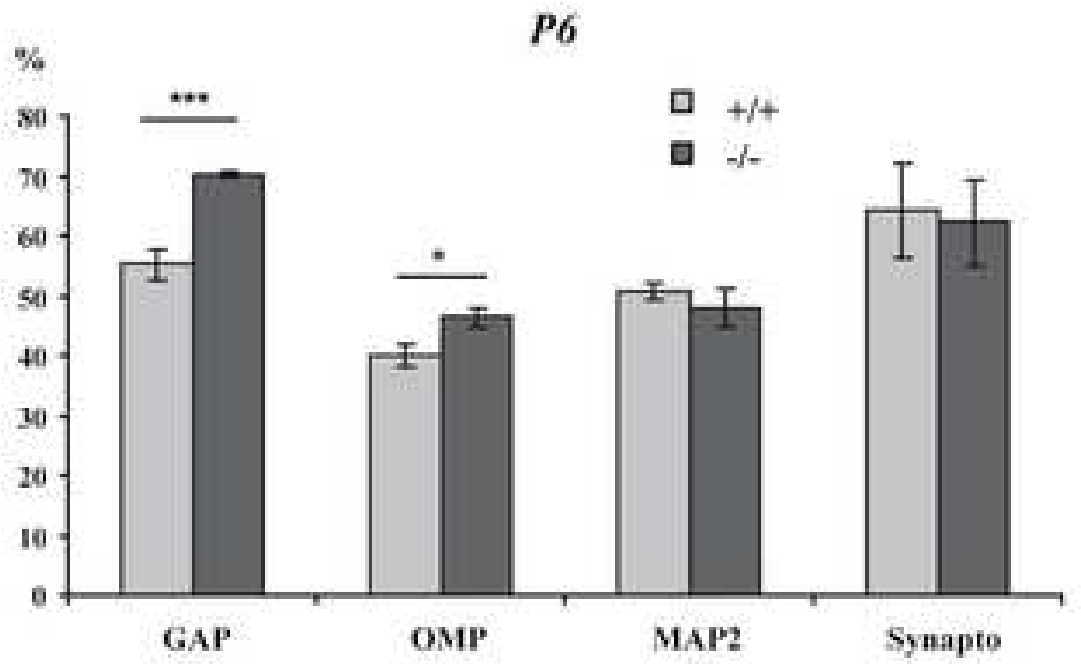

ADULT

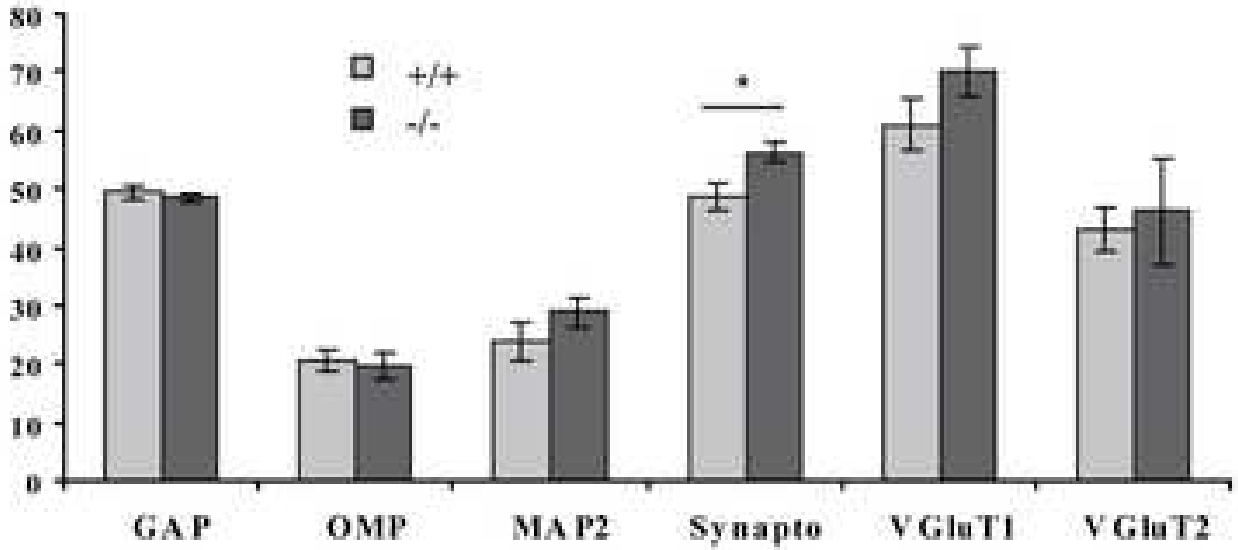

Figure 9
$\mathbf{A}^{\prime}$
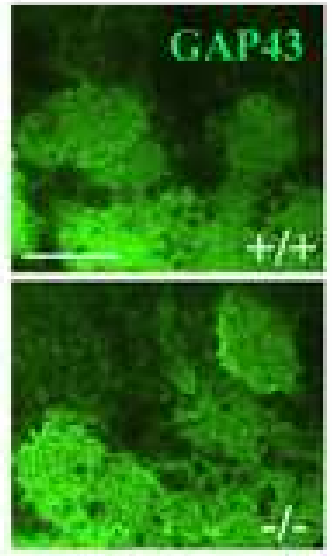

B'
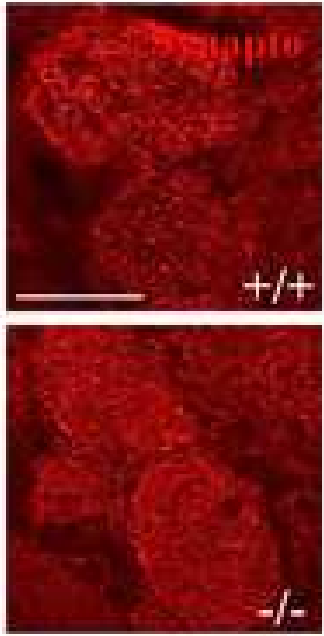


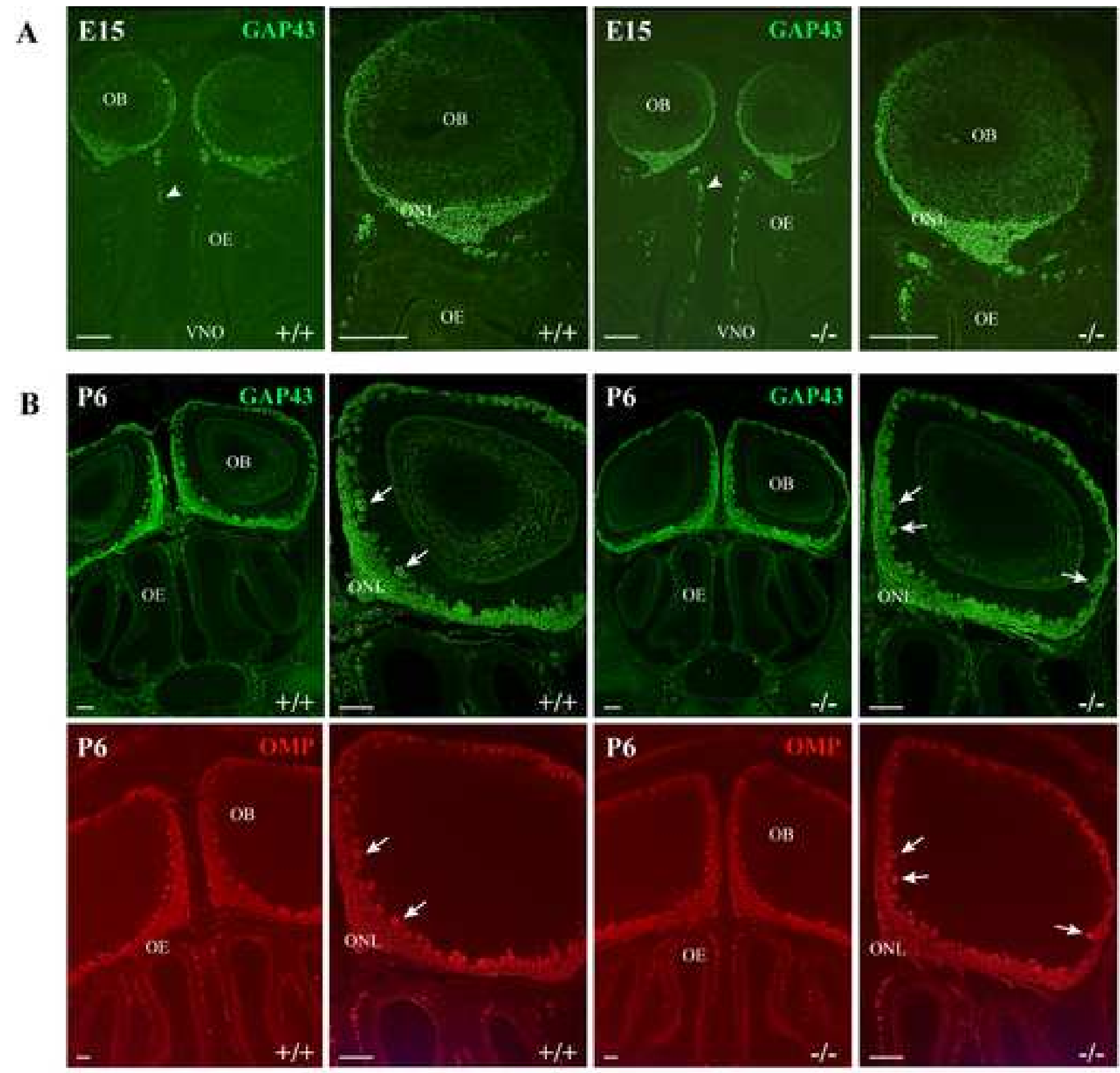

Supplementary Figure 1 


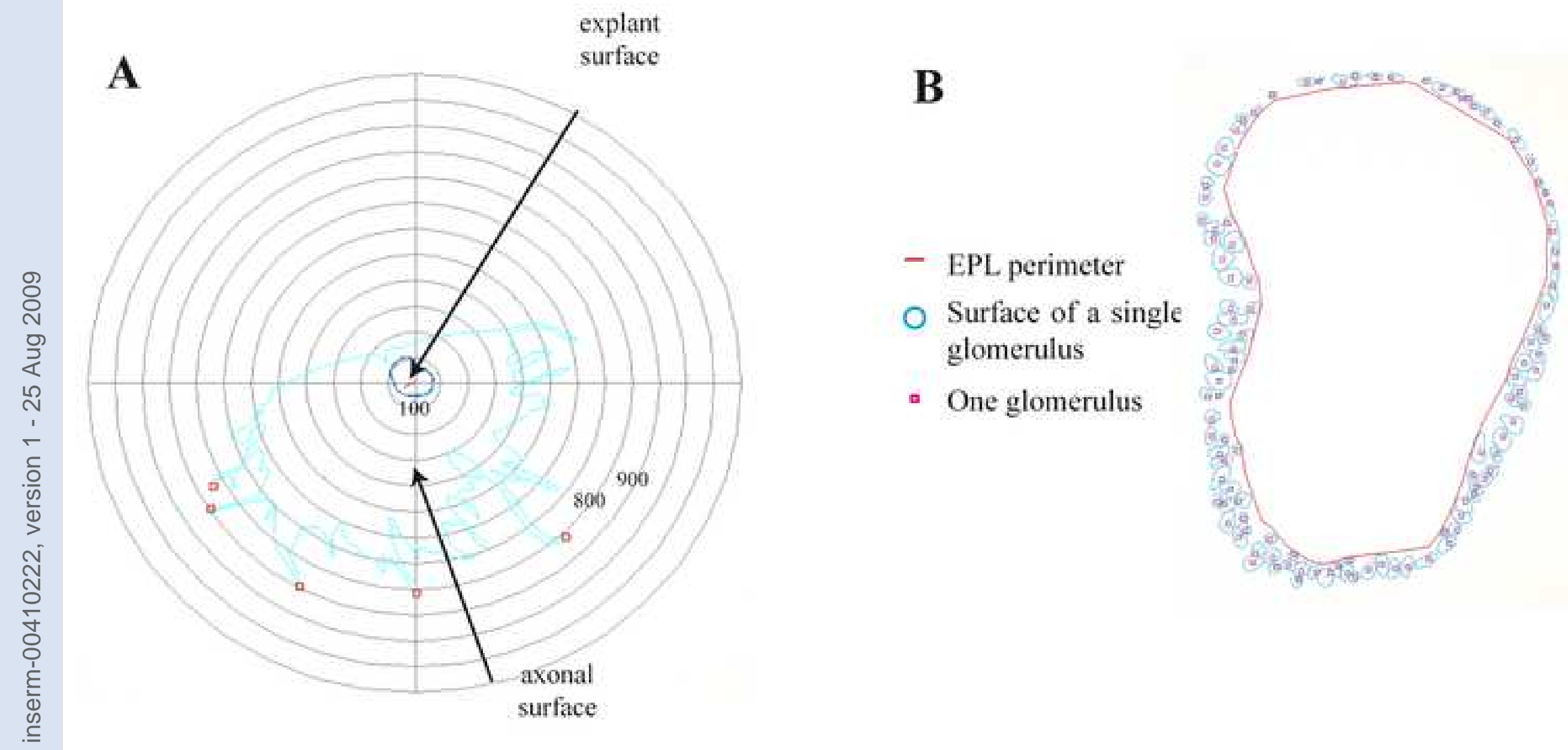

Supplementary Figure 2 


\section{Supplementary Figure 3}

Click here to download high resolution image

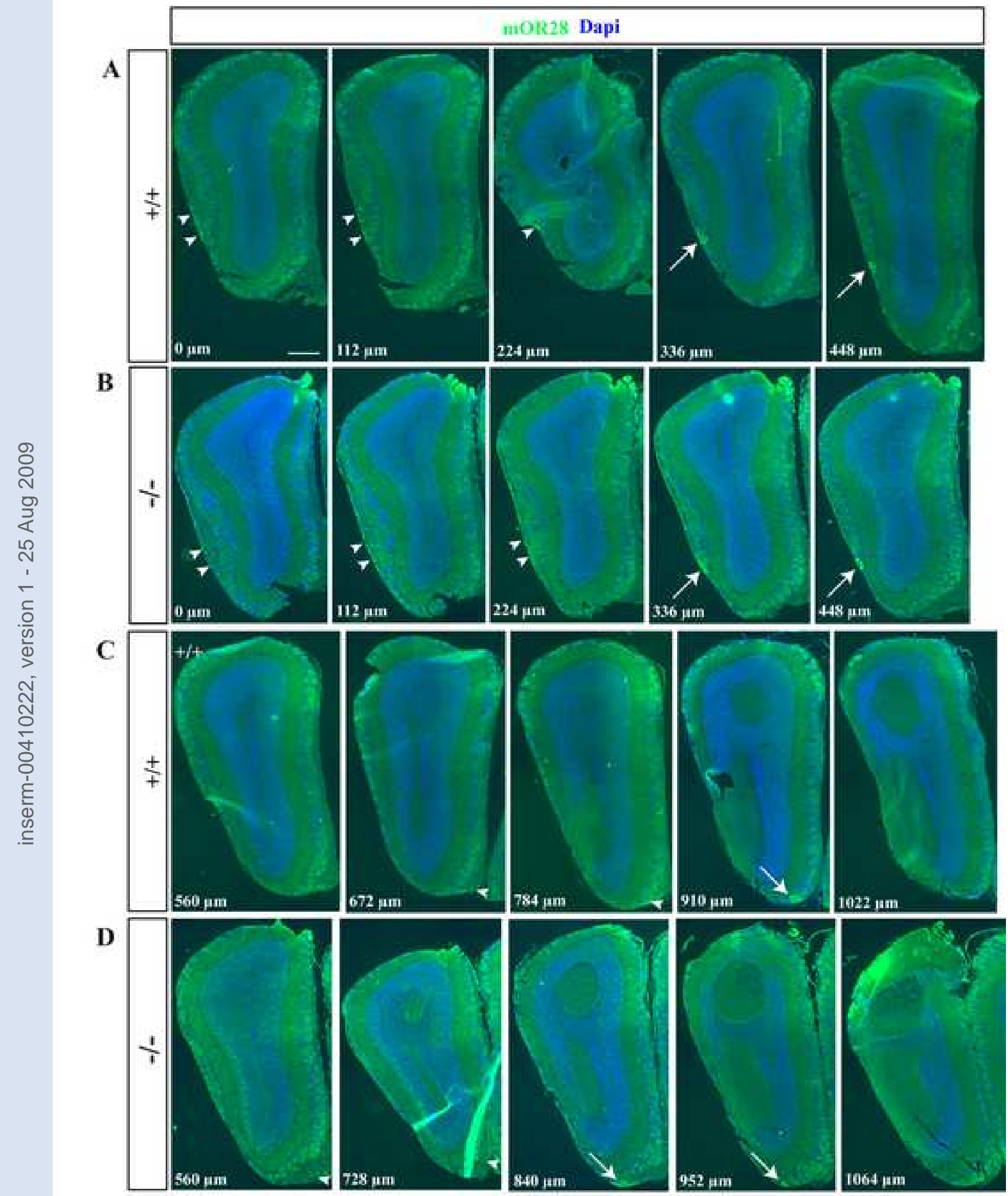

Suppleme,tary Figure 3 


\begin{tabular}{|c|c|c|c|c|c|c|}
\hline & \multicolumn{3}{|c|}{ P6 } & \multicolumn{3}{|c|}{ Adult } \\
\hline & WT & STOP $^{-/-}$ & P-value & WT & STOP $^{--}$ & P-value \\
\hline GAP43 & $55.2 \pm 2.5 \%$ & $70.2 \pm 0.4 \%$ & $\mathrm{p}=0.004$ & $49.3 \pm 1.3 \%$ & $48.6 \pm 0.7 \%$ & $\mathrm{p}=0.64$ \\
\hline OMP & $39.9 \pm 1.7 \%$ & $46.3 \pm 1.5 \%$ & $\mathrm{p}=0.05$ & $20.5 \pm 1.7 \%$ & $19.8 \pm 2.4 \%$ & $\mathrm{p}=0.81$ \\
\hline МАP2 & $50.7 \pm 1.3 \%$ & $48 \pm 3.1 \%$ & $\mathrm{p}=0.48$ & $28.9 \pm 3.3 \%$ & $28.8 \pm 2.6 \%$ & $\mathrm{p}=0.30$ \\
\hline Synaptophysin & $64.1 \pm 7.7 \%$ & $62.3 \pm 7.2 \%$ & $\mathrm{p}=0.86$ & $48.7 \pm 2.2 \%$ & $56.2 \pm 1.7 \%$ & $\mathrm{p}=0.05$ \\
\hline VGluT1 & & & & $60.9 \pm 4.5 \%$ & $70.1 \pm 4.4$ & $\mathrm{p}=0.21$ \\
\hline VGluT2 & & & & $42.9 \pm 3.8 \%$ & $46.1 \pm 8.9$ & $\mathrm{p}=0.76$ \\
\hline
\end{tabular}

Table 1: Quantification of the glomerular compartmentalization

Results are presented as mean \pm s.e.m, $\mathrm{n}=3$ animals per genotype and per age. 


\begin{tabular}{|c|c|c|c|c|c|c|}
\hline & \multicolumn{3}{|c|}{ Primary antibody } & \multicolumn{3}{|c|}{ Secondary antibody } \\
\hline & Name (host) & Dilution & Provider & Name & Dilution & Provider \\
\hline \multirow{3}{*}{ 它 } & 23C (rabbit) & $1 \cdot 200$ & \multirow{3}{*}{$\begin{array}{l}\text { Dr A. Andrieux, } \\
\text { Cytoskeleton Lab, } \\
\text { Grenoble, France }\end{array}$} & Swine anti-rabbit FITC or & $1 \cdot 100$ & Dako and Vector \\
\hline & $\alpha \mathrm{E}$ (rabbit) & 1.200 & & or Goat anti-rabbit FITC & 1.100 & \\
\hline & 175 (mouse) & $1: 300$ & & $\begin{array}{l}\text { Horse anti-mouse FITC } \\
\text { (pre-absorbed in rat) }\end{array}$ & $1: 100$ & Vector Lab \\
\hline \multirow{12}{*}{ 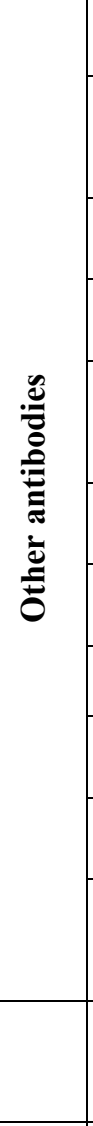 } & $\begin{array}{l}\text { anti-GAP43 } \\
\text { (mouse) }\end{array}$ & $1: 600$ & Sigma (clone GAP-7B10) & Horse anti-mouse FITC & $1: 200$ & Vector Lab \\
\hline & anti-OMP (goat) & $1: 800$ & $\begin{array}{c}\text { gift from Dr F. Margolis, } \\
\text { University of Maryland, } \\
\text { USA. }\end{array}$ & Rabbit anti-goat TRITC & $1: 100$ & Sigma \\
\hline & $\begin{array}{l}\text { anti-MAP2 } \\
\text { (mouse) }\end{array}$ & $1: 400$ & Sigma (clone HM-2) & Goat anti-mouse TRITC & $1: 100$ & AbCys \\
\hline & $\begin{array}{l}\text { anti-synaptophysin } \\
\text { (mouse) }\end{array}$ & $1: 300$ & Sigma (SVP38) & Goat anti-mouse TRITC & $1: 100$ & AbCys \\
\hline & $\begin{array}{l}\text { anti-VGluT1 } \\
\text { (guinea pig) }\end{array}$ & $1: 2500$ & Chemicon (AB5905) & $\begin{array}{l}\text { Donkey anti-guinea pig } \\
\qquad \mathrm{Cy} 2\end{array}$ & $1: 200$ & $\begin{array}{c}\text { Jackson } \\
\text { Immunoresearch } \\
\text { lab }\end{array}$ \\
\hline & $\begin{array}{l}\text { Anti-VGluT2 } \\
\text { (rabbit) }\end{array}$ & $1: 1000$ & $\begin{array}{c}\text { Synaptic Systems } \\
(135403) \\
\end{array}$ & $\begin{array}{c}\text { Donkey anti-rabbit } \\
\text { Alexa488 }\end{array}$ & $1: 1000$ & $\begin{array}{l}\text { Molecular } \\
\text { Probes }\end{array}$ \\
\hline & $\begin{array}{l}\text { anti-peripherin } \\
\text { (rabbit) }\end{array}$ & $1: 200$ & Chemicon (AB1530) & Swine anti-rabbit FITC & $1: 100$ & Dako \\
\hline & anti-GFAP (rabbit) & $1: 200$ & Dako (Z334) & Swine anti-rabbit TRITC & $1: 100$ & Dako \\
\hline & anti-GFAP (mouse) & $1: 200$ & $\begin{array}{l}\text { BD Pharmingen (cocktail } \\
\text { clones 4A11, 1B4, 2E1) }\end{array}$ & Goat anti-mouse TRITC & $1: 100$ & AbCys \\
\hline & 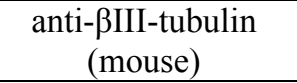 & $1: 800$ & Sigma (clone SDL.3D10) & $\begin{array}{l}\text { Horse anti-mouse } \\
\text { biotinylated }\end{array}$ & $1: 200$ & Vector Lab \\
\hline & $\begin{array}{l}\text { anti-mOR256-17 } \\
\text { (rabbit) }\end{array}$ & $1: 400$ & $\begin{array}{c}\text { gift from Dr H. Breer } \\
\text { University of Hohenheim, } \\
\text { Germany. }\end{array}$ & Goat anti-rabbit FITC & $1: 200$ & Vector Lab \\
\hline & $\begin{array}{l}\text { anti-mOR28 } \\
\text { (rabbit) }\end{array}$ & $1: 5000$ & $\begin{array}{l}\text { gift from Dr R. Axel, } \\
\text { Columbia University, } \\
\text { USA }\end{array}$ & $\begin{array}{l}\text { Donkey anti-rabbit } \\
\text { Alexa488 }\end{array}$ & $1: 1000$ & $\begin{array}{l}\text { Molecular } \\
\text { Probes }\end{array}$ \\
\hline 离 & & & & Phalloidin-TRITC & $1: 200$ & Sigma (P1951) \\
\hline
\end{tabular}

Table 2: Summary of the different antibodies used in this study 